\title{
Radiometric calibration accuracy and stability of GOES-16 ABI Infrared radiance
}

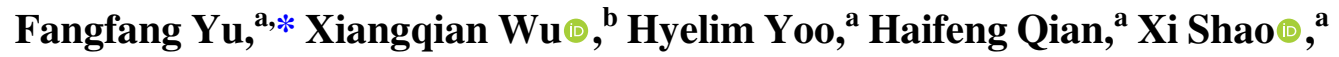 \\ Zhipeng Wang, ${ }^{a}$ and Robert Iacovazzic \\ ${ }^{a}$ University of Maryland, ESSIC, College Park, Maryland, United States \\ ${ }^{b}$ NOAA/NESDIS/STAR, College Park, Maryland, United States \\ ${ }^{\mathrm{c}} \mathrm{GST}$, Inc., Greenbelt, Maryland, United States
}

\begin{abstract}
The Advanced Baseline Imager (ABI) is the primary instrument onboard NOAA's current generation of Geostationary Operational Environment Satellites R-series (GOES-R) satellites, measuring the reflected and emitted energy from the Earth. It consists of 16 channels, 10 in the thermal infrared (IR) and 6 in the solar reflective spectrum. Being the first in the GOESR series satellites, GOES-16 was launched on November 19, 2016, and became operational as GOES-East at $75.2^{\circ} \mathrm{W}$ since December 18,2017 . We examine the radiometric calibration accuracy and stability of GOES-16 ABI IR radiance since its first light in January 2017, including the effects of two major updates of the GOES-R Ground Segment processing for the IR channels in October 2017, and June 2018. Using measurements by multiple hyperspectral radiometers from low Earth orbit satellites as references, it is found that, when converted to scene brightness temperature of $300 \mathrm{~K}$, the calibrated ABI IR radiance is accurate within $0.13 \mathrm{~K}$ for Ch16 $(13.3 \mu \mathrm{m})$, within $0.06 \mathrm{~K}$ for channel $12(9.6 \mu \mathrm{m})$, and within $0.05 \mathrm{~K}$ for the other IR channels. This is an order of magnitude better than the requirement of $1 \mathrm{~K}$. Since June, 2018, the radiometric calibration of GOES-16 ABI IR channels has been temporally stable, spatially uniform within the ABI full-disk field of view, absent of diurnal and seasonal variations, and invariant within various timelines. Other than short term disruptions as noted in the Calibration Event Log, GOES-16 ABI IR Level $1 \mathrm{~b}$ products since June 19, 2018, is a reliable reference for satellite intercomparison or intercalibration studies. () The Authors. Published by SPIE under a Creative Commons Attribution 4.0 International License. Distribution or reproduction of this work in whole or in part requires full attribution of the original publication, including its DOI. [DOI: 10.1117/1.JRS.15.048504]
\end{abstract}

Keywords: GOES-16; ABI; infrared calibration; GEO-LEO inter-calibration; calibration spatial uniformity; calibration temporal uniformity.

Paper 210587 received Sep. 7, 2021; accepted for publication Nov. 23, 2021; published online Dec. 10, 2021.

\section{Introduction}

The Advanced Baseline Imager (ABI) is the primary weather instrument onboard the current generation of Geostationary Operational Environmental Satellite R-Series (GOES-R), operated by the National Oceanic and Atmospheric Administration (NOAA) to measure the reflected and emitted energy from the Earth surface and atmosphere in the western hemisphere. There are a wide variety of uses for the $\mathrm{ABI}$ imagery in weather monitoring, forecasting, and environmental change studies. While observations from the ABI solar reflective wavelengths are used for the detections of aerosol, haze, clouds, cirrus, and snow cover, the product generations of aerosol optical depth, aerosol particle sizes, clear-sky masks, cloud and moisture imagery, and the studies of vegetation, insolation, and many others, the ABI infrared (IR) data are used to generate numerous atmospheric and land surface products, including cloud and moisture products, derived motion winds, fire, hurricane intensity, volcanic ash, ozone, $\mathrm{CO}_{2}$, sea surface temperature, land surface temperature, snow/fog cover, rainfall rate, etc. ${ }^{1}$ The IR products are also critical inputs to numerical weather prediction models at the National Weather Service. All these applications and products are derived from the calibrated ABI radiance. The accurate radiometric

*Address all correspondence to Fangfang Yu, Fangfang.yu@noaa.gov 
calibration of ABI IR imagery is thus fundamental to accurate weather forecasting and environmental change studies in the United States (US) and its neighboring environs.

GOES-16 (G16) is the first of the four GOES-R satellites carrying the new multispectral ABI instrument. It was launched on November 19, 2016, and became operational in the GOES-East position at $75.2^{\circ} \mathrm{W}$ on December 18, 2017, after a yearlong intensive post-launch testing (PLT) period and post-launch product testing (PLPT) to validate instrument performance and the radiance products in the check-out positions. It has been providing high quality of Earth imagery since the "first light" measurements in the middle of January 2017. Two major GOES-R ground system (GS) updates were conducted to improve the G16 IR radiometric calibration accuracy in the early in-orbit time. The first major GS update was conducted on October 19, 2017, aiming to improve the spatial uniformity of the calibrated IR radiance, and the second major update occurred on June 19, 2018, to improve the absolute calibration accuracy of the IR data. Several methods were applied to monitor and evaluate the ABI IR radiometric calibration accuracy and variations at various spatial and temporal scales. ${ }^{2}$ This paper is an overall evaluation of the G16 ABI IR radiometric calibration accuracy and variation since January 2017, with particular emphasis on the impacts of two major GS upgrades.

The paper is organized as follows: after the introduction section, the ABI IR calibrationrelated background information is described in Sec. 2, which includes the instrument design, calibration algorithm, data collection schemes, and GS data processing; the methods and data used in this study are described in Sec. 3. The results are discussed in Sec. 4, and Sec. 5 offers conclusions of our study's findings.

\section{ABI IR Calibration}

\section{1 $A B$ I Instrument}

The ABI instrument consists of 16 spectral channels to measure the Earth's radiance, with six within the visible and near-infrared (VNIR) spectral wavelength range from 0.47 to $2.25 \mu \mathrm{m}$ and 10 within the IR wavelength from 3.9 to $13.3 \mu \mathrm{m}$. It has two independent scan mirrors (SMs), the East-West (EW) and North-South (NS) SMs, to enable pointing to any position within the ABI field of regard (FOR). The energy reaching the aperture is reflected by these two SMs, through the four mirror anastigmat telescope and then split into three FPMs where the detectors are embedded. ${ }^{3}$ The detectors of the six VNIR channels (Ch01 to 06) are embedded in the VNIR FPM, while the mid-wave infrared (MWIR) FPM is carrying the detectors for the five spectral channels from 3.9 to $8.5 \mu \mathrm{m}$ (Ch07 to 11), and the long-wave infrared (LWIR) FPMs encompasses the five spectral channels from 9.6 to $13.3 \mu \mathrm{m}$ (Ch12 to 16). The IR spectral characteristics are listed in Table 1.

Each ABI IR channel has 328 or 404 rows of detectors in the focal plane array down-linked for ground data processing, and each row has six detectors for redundancy. In operation, only one detector from each row is read out and downlinked for ground system operational data processing. This selected detector is called best detector select (BDS). During the mission life, the BDS detector response may become unstable or saturated, resulting in perceptible striping in the images. A BDS update is then needed to replace the malfunction detector with a candidate which has a noise performance known to be within specification based on an early PLT/PLPT on-orbit testing. Accordingly, the calibration performance of each individual detector is closely monitored during its mission life, together with the $\mathrm{ABI}$ image quality and many other $\mathrm{ABI}$ calibration-related key telemetry parameters. Up to the date that this paper was submitted, G16 has had a total of 16 BDS updates for all the 10 IR channels. These activities are carried out by the GOES-R ABI Calibration Working Group, which has a website dedicated to the NOAA's geostationary weather instrument calibration and data performance in Ref. 36.

\subsection{ABI Operational Scan Modes and Timelines}

The ABI instrument collects Earth data from three standard geographic scenes: full-disk (FD) Earth of the Western Hemisphere, Continental United States (CONUS), and Mesoscale (MESO) 
Table $1 \mathrm{ABI} I \mathrm{R}$ spectral channel characteristics.

\begin{tabular}{|c|c|c|c|c|c|c|}
\hline $\begin{array}{l}\text { Channel } \\
\text { no. }\end{array}$ & $\begin{array}{c}\text { Center } \\
\text { wavelength } \\
(\mu \mathrm{m})\end{array}$ & FPM & Descriptive name & $\begin{array}{l}\text { Valid } \\
\text { detector } \\
\text { rows }\end{array}$ & $\begin{array}{l}\text { Detector } \\
\text { columns } \\
\text { per row }\end{array}$ & $\begin{array}{l}\text { Pixel } \\
\text { spatial } \\
\text { resolution } \\
\text { at nadir }\end{array}$ \\
\hline Ch07 & 3.9 & MWIR & Shortwave window & 328 & 6 & 2 \\
\hline Ch08 & 6.2 & MWIR & Upper-level water vapor & 328 & 6 & 2 \\
\hline Ch09 & 6.9 & MWIR & Midlevel water vapor & 328 & 6 & 2 \\
\hline Ch10 & 7.3 & MWIR & $\begin{array}{l}\text { Lower/midlevel water } \\
\text { vapor }\end{array}$ & 328 & 6 & 2 \\
\hline Ch11 & 8.4 & MWIR & Cloud-top phase & 328 & 6 & 2 \\
\hline Ch12 & 9.6 & LWIR & Ozone & 404 & 6 & 2 \\
\hline Ch13 & 10.3 & LWIR & Clean longwave window & 404 & 6 & 2 \\
\hline Ch14 & 11.2 & LWIR & Longwave window & 404 & 6 & 2 \\
\hline Ch15 & 12.3 & LWIR & Dirty longwave window & 404 & 6 & 2 \\
\hline Ch16 & 13.3 & LWIR & $\mathrm{CO}_{2}$ & 404 & 6 & 2 \\
\hline
\end{tabular}

regions. ${ }^{4}$ The FD is a circle with a 17.4-deg angular diameter from the subsatellite nadir to the Earth's limb. The CONUS scene covers an area of about $5000 \mathrm{~km} \mathrm{EW} \times 3000 \mathrm{~km}$ NS, and the MESO scene is approximately $1000 \mathrm{~km} \times 1000 \mathrm{~km}$. While the FD and CONUS images are collected with fixed scan regions, the MESO images can be scanned at any positions within the ABI FOR due to the agile reposition capability of the ABI SMs.

The combination of the FD, CONUS, and MESO Earth scenes, together with the blackbody Internal Calibration Target (ICT), spacelook (SPL), and star observations, forms the ABI Earth scan modes. The data collected from the ICT and SPL scans are used for the radiometric calibration, and the star observations are for image navigation and registration (INR). Three standard scan modes have been used for ABI operational data collections, each of which includes one FD Earth scene at a unique time interval: mode 3 at every 15 min, mode 6 at every $10 \mathrm{~min}$, and mode 4 at every $5 \mathrm{~min}$. Mode 3 was used as the default operation before April 2, 2019, after which it was replaced by mode 6 . Mode 4 , which consists of only the FD Earth scene without CONUS and MESO scenes, was mainly used in the PLT/PLPT period, and in operation, it is only used together with the solar calibration timeline in the solar calibration events. Therefore, the mode 3 and mode 6 data are mainly analyzed in this study.

The ABI timeline that defines the sequence of Earth and calibration target observations is configurable. The operational timelines used for G16 are called mode $3 \mathrm{E}$ and mode $6 \mathrm{~A}$, respectively. Figure 1 shows their time-time diagrams. Mode 3E consists of one FD, three CONUS, and 30 MESO Earth scene scans, and mode 6A has one FD, two CONUS, and 20 MESO scene scans. Each FD image consists of 22 swaths, CONUS of six swaths, and MEOS of two swaths. All the swaths of each frame are aligned vertically. The CONUS, and MESO swaths, as well as the radiometric and geometric calibration target scans, are interleaved with the FD swaths. The SPL measurements are conducted at an interval of no more than about $30 \mathrm{~s}$ to provide the detector dark current as the background offset. They are acquired at the beginning (from midnight to noon) or end (from noon to midnight) of the FD swaths or near the equator. To enhance the star signals, the time integration factor used for the star observations is higher than that used for the Earth scans.

To facilitate intensive observations of severe weather and disastrous environmental changes, the MESO scans are intermittently grouped into two groups as MESO1 (M1) and MESO2 (M2). Most of the time, the M1 and M2 images are used to monitor targets at two different areas at the interval of every $1 \mathrm{~min}$. 

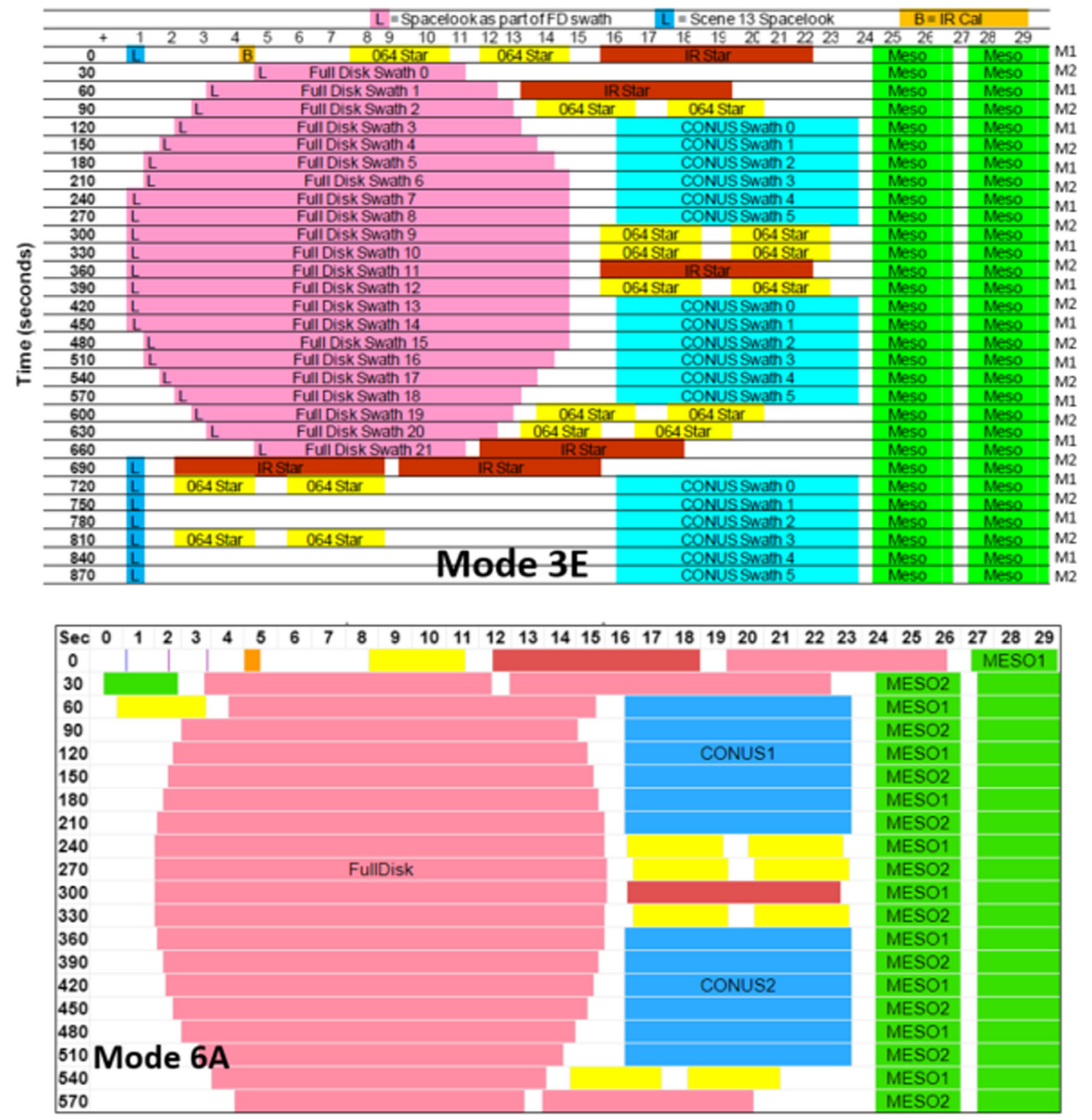

Fig. 1 The time-time diagrams of two mostly used G16 operational scan modes, mode 3E (upper) and mode $6 \mathrm{~A}$ (lower). Pink, blue, and green represent the time scanning the FD, CONUS, and MESO sectors, respectively, and orange for the ICT look. The yellow and red stand for the visible and IR star-looks, respectively. In mode 3E (upper), the SPL is conducted in the space west to the Earth for the data collected by satellite from midnight to noon. M1 and M2 in the upper panel stand for MESO1 and MESO2, respectively.

\subsection{ABI IR Calibration Algorithms}

ABI applies the two-point calibration algorithm with a nonlinear response function for the radiometric calibration. The warm blackbody ICT and cold SPL are the two onboard calibration targets for the IR channels. The radiance received by each detector is corrected for the energy contributed by the reflectance (emissivity) from the two SMs. The coating absorptions of the SMs, if not corrected, can result in incidence angle-dependent radiance. ${ }^{5}$

The equations of the IR calibration algorithm for each IR detector can be described as follows: ${ }^{6}$

$$
m=\frac{L_{\mathrm{ICT}}-q \Delta C_{\mathrm{ICT}}^{2}+\left(L_{\mathrm{EW} @ \mathrm{ICT}}+L_{\mathrm{NS} @ \mathrm{ICT}}\right)-\left(L_{\mathrm{EW} @ \mathrm{SPL}}+L_{\mathrm{NS} @ \mathrm{SPL}}\right)}{\Delta C_{\mathrm{ICT}}},
$$

where $m$ is the detector linear coefficient, also called the gain value in the ABI calibration. It is updated at every ICT event; $q$ is the fixed detector nonlinear responsivity, which was measured before the satellite launch; $L_{\mathrm{ICT}}$ is the band-averaged spectral radiance at the ICT view; $L_{\mathrm{EW} @ \mathrm{ICT}}$ 
and $L_{\mathrm{NS} @ \mathrm{ICT}}$ are spectral radiance contributed from the EW and NS SMs at the ICT view time, respectively; $L_{\mathrm{EW} @ S P L}$ and $L_{\mathrm{NS} @ \mathrm{SPL}}$ are spectral radiance contributed from the EW and NS SMs at the SPL view time conducted right before the ICT view, respectively; and $\Delta C_{\mathrm{ICT}}$ is the ICT count offset to the background level that is measured with an SPL scan right before the ICT look:

$$
\Delta C_{\mathrm{ICT}}=C_{\mathrm{ICT}}-C_{\mathrm{SPL}, \mathrm{ICT}},
$$

where $C_{\mathrm{ICT}}$ is the mean of the measured counts at the ICT view and $C_{\mathrm{SPL}, \mathrm{ICT}}$ is the mean of the SPL counts collected right before the ICT view.

The scene radiance of the Earth view $L_{\mathrm{EV}}$ can be determined as follows:

$$
L_{\mathrm{EV}}=\frac{m \Delta C_{\mathrm{EV}}+q \Delta C_{\mathrm{EV}}^{2}-\left(L_{\mathrm{NS} @ \mathrm{EV}}+L_{\mathrm{EW} @ \mathrm{EV}}\right)+\left(L_{\mathrm{NS} @ \mathrm{SPL}}+L_{\mathrm{EW} @ \mathrm{SPL}}\right)}{\rho_{\mathrm{NS} @ \mathrm{EV}} \rho_{\mathrm{EW} @ \mathrm{EV}}},
$$

where $L_{\mathrm{NS} @ \mathrm{EV}}$ and $L_{\mathrm{EW} @ \mathrm{EV}}$ are the spectral radiance contributed from the NS and EW SMs at the time of the Earth view sample, respectively; $L_{\mathrm{NS} @ S P L}$ and $L_{\mathrm{EW} @ S P L}$ are the spectral radiance contributed from these two SMs at the most recent SPL time before the Earth view; $\rho_{\mathrm{NS} @ \mathrm{EV}}$ and $\rho_{\mathrm{EW} @ \mathrm{EV}}$ are the reflectances of the EW and NS SMs at the angles as they scan the Earth view, respectively; and $\Delta C_{\mathrm{EV}}$ is the Earth view count $\left(C_{\mathrm{EV}}\right)$ offset to the mean count of the latest SPL before the Earth view $\left(C_{\mathrm{SPL}}\right)$, assuming no change of background energy since then.

$$
\Delta C_{\mathrm{EV}}=C_{\mathrm{EV}}-C_{\mathrm{SPL}}
$$

The moon can frequently appear in the space within the ABI FOR. Some detector SPL counts may be contaminated when the moon transits across the SPL position at the time of the SPL view. The contaminated SPL leads to the erroneous calculation of Eq. (2) and/or Eq. (4) and thus results in an inaccurately calibrated radiance that causes striping in the images. A lunar intrusion rejection algorithm is thus operationally implemented to use the previous mean SPL count to replace the contaminated SPL value. This algorithm assumes that the detector should be stable, and this substituted SPL count should be soon updated with the actual measurements when the moon moves away from the calibration scenes. However, shifts of detector response, caused by a sudden change in the background dark current, are occasionally observed in operation. A sudden increase in the SPL count might trigger the function of the lunar intrusion rejection algorithm which latched the SPL count to a constant value and thus causes striping. This is the major cause of striping in the ABI images. The latched SPL counts, if not saturated, sometimes may be released naturally. It can also be released manually with human intervention to refresh the SPL count in the operational service memory, or through a BDS update if the detector is under performing or saturated. Between June 1, 2017 and June 22, 2021, about 30 apparent striping events-lasting from a few hours to several days - were reported in the G16 IR images when the ABI L1B radiance products are available to the public. ${ }^{37}$ An improvement in the lunar intrusion rejection algorithm was operationally implemented on June 22, 2021, to prevent the latch-up of SPL count for a single detector.

The ICT and SM radiance in Eqs. (1) and (2) are computed from the temperature measured from a series of platinum resistance thermometers (PRTs) embedded on the blackbody and SM surfaces. While the ICT temperature is generally controlled at 302K, the SM temperatures are not controlled (Fig. 2). The temperature of the two SMs varies up to more than $30 \mathrm{~K}$ diurnally, and the diurnal magnitude varies seasonally.

\subsection{Level1B (L1B) Radiance Data Processing and Data Dissemination}

The ABI L1B radiance products are disseminated with a fixed-grid coordinate system that uses a set of static pixel locations projected relative to the ideal location of a satellite in geostationary orbit. ${ }^{14}$ In the GOES-R ABI ground operational processing, the raw counts of IR detector samples are first radiometrically calibrated to radiance using Eqs. (1)-(4) then navigated and resampled to the fixed grid coordination. A channel-dependent Sinc Function kernel is used in the resampling process to derive the radiance at each fixed pixel from the neighboring 


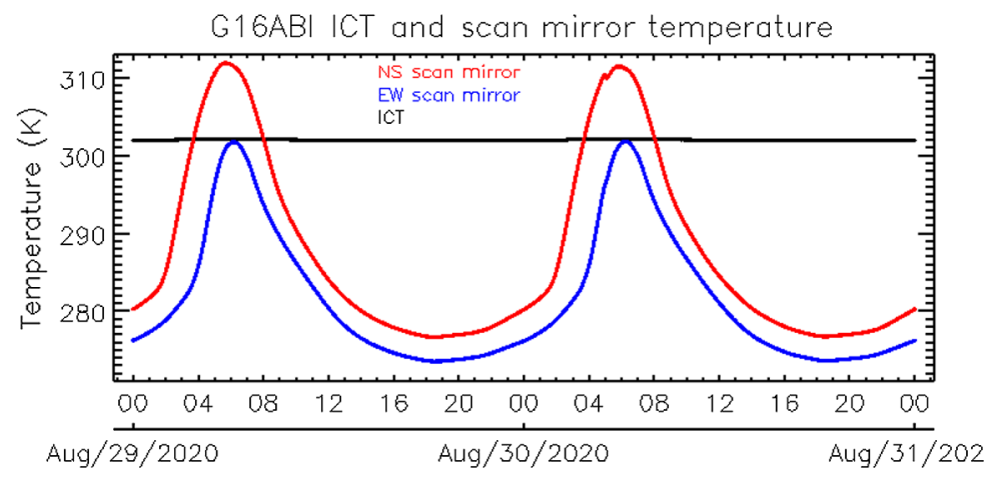

Fig. 2 Time-series of ICT (in black), NS, and EW scan-mirror temperature on August 29 and 30, 2020.

$4 \times 4$ Earth scene spatial samples. After resampling, the pixel angular distance from the satellite in the IR L1b imagery is $56 \mu \mathrm{rad}$, which corresponds to $2 \mathrm{~km}$ at satellite nadir (Table 1).

\section{Methods}

Two methods are used in this study to examine radiometric calibration accuracy, spatial uniformity, and temporal stability. The first method is to compare the geostationary measurements (GEO) to hyperspectral IR radiometers onboard the low Earth orbit (LEO) satellites to evaluate the calibration accuracy and the uniformity within the FOR. The calibration stability at diurnal, seasonal, and long-term scales is also evaluated with this method. The second method is MESOto-MESO radiance variation to examine the calibration variation within a timeline. These two methods are described below.

\subsection{GEO-LEO Intercalibration}

\subsubsection{GEO-LEO reference instruments}

Many studies have shown that hyperspectral radiometers onboard LEO satellites, including the Infrared Atmospheric Sounding Interferometer (IASI) onboard Metop satellites operated by the European Organisation for the Exploitation for Meteorological Satellites (EUMETSAT) and the Cross-track Infrared Sounder (CrIS) on-board the Suomi National Polar-Orbiting Partnership (SNPP) and NOAA-20 (N20) satellites operated by NOAA, are well calibrated and stable. ${ }^{7-11}$ Although they are built and operated by different agencies in different countries, the calibration differences among these instruments are very small. ${ }^{11-13}$ Therefore, both IASI and CrIS instruments are used to examine the ABI IR radiometric calibration performance. These two series of LEO sun-synchronous satellites have different orbital configurations. The Metop satellites have local equatorial crossing time (LECT) of 09:30/21:30, while the satellites carrying the CrIS instruments have LECT of 01:30/13:30. This difference in the orbit configurations allows the LEO satellites to underpass the GEO spatial domain at different local times, providing an opportunity to assess the ABI radiometric calibration performance at different times in a day. ${ }^{14}$ In fact, these hyperspectral radiometers are recommended as references by the Global Satellite Inter-Calibration System (GSICS) community ${ }^{15}$ for the intercalibration of broadband IR channels.

A total of four LEO instruments are used in this study, including the two IASI onboard Metop-B and Metop-C and the two CrIS onboard SNPP and N20. The spectral response functions (SRF) of the 10 ABI IR channels and the simulated spectra of IASI and CrIS are shown in Fig. 3. While the continuous IASI spectrum covers the full SRFs of all the ABI IR channels, the spectral gaps between the three CrIS bands result in incomplete spectral coverage for ABI Ch07, Ch08, and Ch11. The performances of these three ABI channels are thus not assessed with the CrIS data in this study. Metop-B/IASI (IASI-B) and SNPP/CrIS have been operating most time 


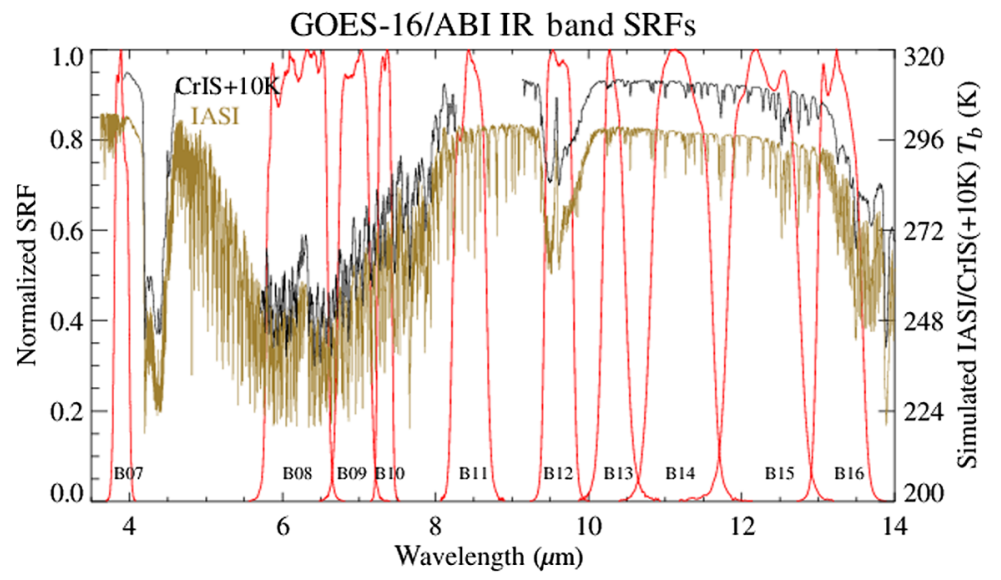

Fig. 3 The SRFs of G16 channels (in red), and the simulated spectra converted to $T_{b}$ for IASI (in gray), and CrIS (in black) over the tropical clear-sky ocean. The CrIS values are plotted by shifting $+10 \mathrm{~K}$.

in the study period. Accordingly, they are used to monitor the ABI IR calibration performance since January 15, 2017. IASI-B, due to its full spectral coverage of all the ABI IR SRFs and its overlapped operational time with G16 so far, is used as the primary reference instrument to assess the absolute calibration accuracy. During the study period, IASI-B experienced a major GS update of the quadratic calibration term for its longwave band on August 2, 2017. ${ }^{11}$ SNPP/ CrIS had a hardware failure on its side 1 electronics on March 26, 2019. The operational generation of the SNPP/CrIS sensor data record was resumed in August, 2019, after the shift to the side 2 electronics, resulting in an over 4-month data gap. It was reported that the impact of the electronics side switch on the SNPP/CrIS radiance calibration was very small and negligible. ${ }^{13}$ On May 21, 2021, SNPP/CrIS experienced an anomaly which resulted in a back-switch to side 1 electronics and loss of midwave CrIS IR data. As the result, SNPP/CrIS data are used till May 20, 2021, in this study. N20/CrIS and IASI-C were launched in November, 2017, and November, 2018, respectively. These two new satellite data are used to ensure the ABI's long-term calibration performance in this study.

\subsubsection{GEO-LEO IR collocation collections}

The GEO-LEO intercalibration is based on the collocated Earth scenes measured by the paired satellites following the procedures recommended by the GSICS community. ${ }^{16,17}$ The collocated GEO-LEO scenes should be temporally, geospatially, geometrically, and spectrally matched. The specific matching criteria are as follows:

Concurrence in time: The time difference between the paired data is less than half of the ABI timeline duration. This is to ensure that one LEO observation can only match one ABI measurement:

$$
\left|t_{\mathrm{GEO}}-t_{\mathrm{LEO}}\right|<\text { time_threshold, }
$$

where $t_{\mathrm{GEO}}$ and $t_{\mathrm{LEO}}$ are the observation time for the GEO and LEO satellites, respectively, and time_threshold is half of the ABI timeline duration: 2.5 min for mode 4 images, 5 min for mode 6 images, and 7.5 min for mode 3 images.

Alignment in viewing geometry: This is to minimize the different contributions from the optical paths of the two instruments to the top-of-atmosphere (TOA) radiances. Assuming that the optical path is proportional to the inverse of the cosine of viewing zenith angle, the maximum difference between the two satellites is set to $1 \%$. No control on the viewing azimuth angle is applied for the collocations: 


$$
\frac{\left|\cos \left(\mathrm{leo}_{\mathrm{zen}}\right)-\cos \left(\mathrm{geO}_{\mathrm{zen}}\right)\right|}{\cos \left(\mathrm{geO}_{\mathrm{zen}}\right)}<\max _{\mathrm{zen}}
$$

where $\max _{\mathrm{zen}}=1 \%, \mathrm{geo}_{\mathrm{zen}}$ and leo $\mathrm{z}_{\text {zen }}$ are the GEO and LEO zenith angles, respectively.

Geospatial matching: The intercalibration is conducted over pseudopixels at the size close to the instantaneous field of views of the LEO instruments. In this study, the ABI data at a $7 \times 7$ window size centered at the LEO footprints are congregated to simulate the radiance of the pseudo-pixels. The area of the $7 \times 7 \mathrm{ABI}$ pixel window size is referred to as the target area. In addition, a larger geocentered area of $21 \times 21 \mathrm{ABI}$ pixel window size, referred to as the environment area, is also used to ensure geospatial matching.

Spectral matching: The matched LEO data are convolved with the ABI SRFs: ${ }^{28}$

$$
R_{\mathrm{GEO}}=\frac{\int_{\nu} R_{\nu} \Phi_{\nu} \mathrm{d} \nu}{\int_{\nu} \Phi_{\nu} \mathrm{d} \nu}
$$

where $R_{\mathrm{GEO}}$ is the simulated ABI radiance, $R_{v}$ is the IASI radiance at wavenumber $v$, and $\Phi_{v}$ is the ABI spectral response at wave number $v$.

Up to about 7000 ABI-IASI collocations and 13,000 ABI-CrIS collocations, due to the different distances between the footprints of these two LEO instruments, can be collected for each satellite pair every day. Figure 4 shows an example of the spatial distribution of the IASI-B collocations collected on June 1, 2020. The collocations are distributed along the LEO orbit tracks all over the ABI FD area. This wide spatial distribution of the collocations provides an opportunity to evaluate the ABI spatial calibration uniformity over the FD images.

\subsubsection{Collocation filtering}

In the GEO-LEO intercalibration, the calibration difference between the two satellites is characterized with the radiance difference from exactly the same targets. However, each collocation criteria allows a certain range to identify sufficient paired measurements needed for analysis. It is thus possible that the collocated radiances are not from the same targets, resulting in relatively

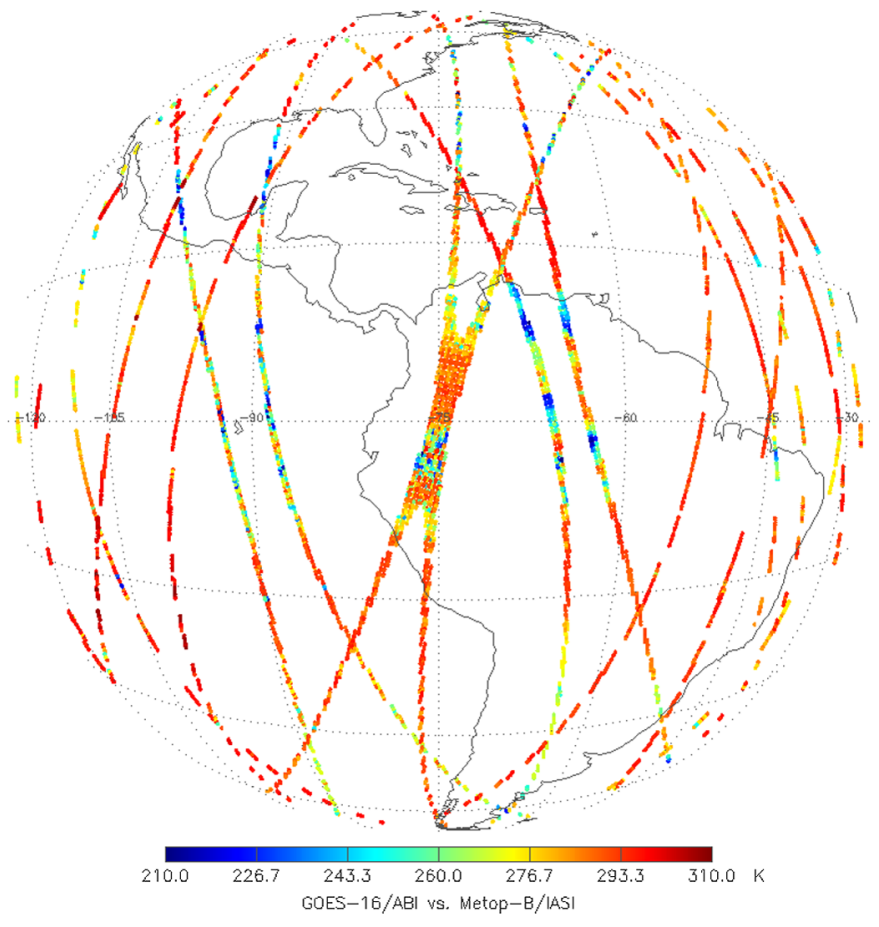

Fig. 4 Spatial distribution of the collocations between GOES-16 ABI and Metop-B IASI on June 1, 2020. Plotted is the brightness temperature of G16 ABI channel 13. 
large uncertainty. Following filtering criteria are applied to reduce the uncertainty caused by possible different targets in the paired satellites.

(1) As recommended by $\mathrm{Wu}$ et al., ${ }^{16}$ the $\mathrm{ABI}$ spectra should be uniform within both the target and environment areas. The uniform scenes are selected with the following two equations:

$$
\begin{aligned}
\mathrm{CoV}_{\text {target }} & =\frac{\sigma_{\text {target }}}{\overline{R_{\text {target }}}}<\text { threshold } \\
\mathrm{CoV}_{\text {env }} & =\frac{\sigma_{\text {env }}}{\overline{R_{\text {env }}}}<\text { threshold, }
\end{aligned}
$$

where $\mathrm{CoV}$ is the coefficient of variance of the radiance for the pixels within the target and environment (env) areas, and $\sigma$ and $\bar{R}$ are the radiance standard deviation and mean values, respectively.

The selection of uniform scenes is to reduce the radiometric differences caused by different spectral targets, e.g., moving targets such as clouds mixed with ocean, land, and/or ice areas, parallax impacts due to nonperfect matched viewing alignment, and possible different geolocation in the two satellites instruments. It can also help to reduce the impact of abnormally calibrated radiance, for example, in the case of image striping, although this occurs rarely as described in Sec. 2.3.

Sensitivity analysis was conducted to assess the uncertainty of the intercalibration results to the spatial, temporal, and viewing geometric criteria. The mean GEO-LEO radiance difference is generally stable to these collocation criteria. The uncertainty of radiance $/ T_{b}$ difference is almost invariant to the time and viewing angle differences, but sensitive to the nonuniformity criteria. As shown in Fig. 5 for ABI versus IASI-B at Ch16, while the mean $T_{b}$ difference is very stable at a variety of $\mathrm{CoV}$ thresholds, the standard deviation of the $T_{b}$ bias linearly increases with the $\mathrm{CoV}$ threshold value, and the number of filtered collocations increases quadratically. The same pattern is observed at the other IR channels. In this paper, the maximum CoV value is set to $3 \%$ or $5 \%$ for all the 10 IR channels, depending on the uncertainty required for different analyses.

(2) Since no constraint is applied to the viewing azimuth angles, the two satellites may view the targets at different viewing azimuth directions. The difference in the viewing azimuth angles can cause a variation in the $T_{b}$ bias over the land area for the window channels during the daytime, possibly due to the nonuniform land heating and emissivity. ${ }^{18}$ Accordingly, only the data over the ocean surface are used for the daytime data analysis, while no such geolocation restriction is applied to the nighttime data.

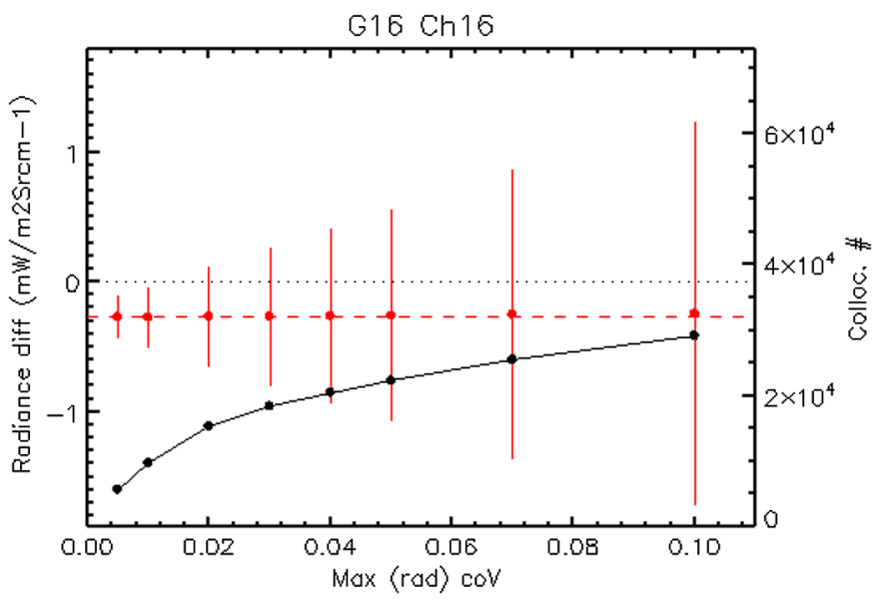

Fig. 5 Sensitivity of mean radiance difference (red dots) and the standard deviation (red vertical lines) to the scene uniformity for ABI versus IASI-B at Ch16. The number of homogenous scenes at different $\mathrm{CoV}$ thresholds is plotted in black on the second $y$ axis. 
(3) Homogenous collocations with large radiance differences may be observed in the homogeneous data, probably due to the residual of parallax impact after the uniform filtering. Further study is needed. A threshold of $10 \mathrm{~K} T_{b}$ difference is applied for all the ABI channels. Note that only several collocations in 1 month, if they occur, can be found and removed with this criterion.

\subsection{MESO-to-MESO Variation}

The calibration variation within a timeline is assessed with MESO images. The two groups of MESO images often continuously view the same areas at two different places for hours to days. As the MESO images are collected after all the radiometric and geometric calibration events within a timeline (Fig. 1), the variation of the MESO radiance, after the correction of natural variation of the Earth, can be used to assess the radiometric calibration stability within a timeline. The procedures are described as follows:

(1) For each group of MESO images (M1 or M2 group), a linear function is used to correct the natural variation of the MESO radiance within one timeline period (10 or $15 \mathrm{~min}$ ). The residual of the linear fitting function $\left(R_{M x, t}^{\prime}\right)$ is used to characterize the calibration variation within the timeline:

$$
R_{M x, t}^{\prime}=R_{M x, t}-\left(a_{x} * t+b_{x}\right),
$$

where $R_{M x, t}$ is the mean radiance value for the MESO image from the $M_{x}$ group ( $x=1$ or 2 for M1 and M2 groups, respectively) collected at time $t$; and $a_{x}$ and $b_{x}$ values are the linear fitting coefficients derived from the time-series of $R_{M x, t}$ in one timeline.

(2) Calculate the mean linear fitting residual value of the MESO residuals for each group $\left(\overline{R_{M x}}\right)$

$$
\overline{R_{M x}}=\operatorname{mean}\left(R_{M x, t}^{\prime}\right)
$$

(3) Normalize each residual to the mean value of each MESO group. This step is to combine the variations of the two MESO groups. Variation in $\Delta R_{M x, t}$ is considered as the calibration variation within the timeline:

$$
\Delta R_{(M x, t)}=R_{(M x, t)}^{\prime}-\overline{R_{M x}}
$$

\section{3 $T_{b}$ difference at Equivalent Brightness Temperature $300 \mathrm{~K}$}

As shown in Eqs (1)-(4), ABI data are calibrated to radiance, which is the primary product in the ABI L1b data. The ABI radiometric calibration accuracy and stability are thus assessed in radiance domain and characterized with the radiance difference and variation to the references. But since brightness temperature is commonly used in the users' community, the radiance difference and variation $(\Delta R)$ are converted to $T_{b}$ difference and variation $(\Delta T)$ at a standard $T_{b}$ which is $300 \mathrm{~K}$ in this study. The ABI radiometric calibration specification is $1 \mathrm{~K}$ at $300 \mathrm{~K}$ equivalent scene $T_{b}:{ }^{19}$

$$
\Delta T=\Delta R / \frac{\partial R_{\lambda}}{\partial T}(\lambda, 300 \mathrm{~K})
$$

where $\frac{\partial R_{\lambda}}{\partial T}(\lambda, 300 \mathrm{~K})$ is the derivative of the Planck function at $T_{b}=300 \mathrm{~K}$ and wavelength $(\lambda)$. 


\section{Results and Discussions}

\subsection{Calibration Variation over Dynamic Range}

The ABI and IASI-B nighttime uniform collocations, which include data from both land and ocean areas, are used to examine the calibration accuracy over the dynamic range for each ABI IR channel. They are examined with the scatterplots of radiance $/ T_{b}$ difference between the two instruments versus the simulated IASI radiance $/ T_{b}$ for the filtered data within a certain period. As an example, in Fig. 6 are the scatterplots for the data collected from June 1, 2020, to June 30, 2020. The spatial uniformity threshold is set to $5 \%$ at each IR channel.
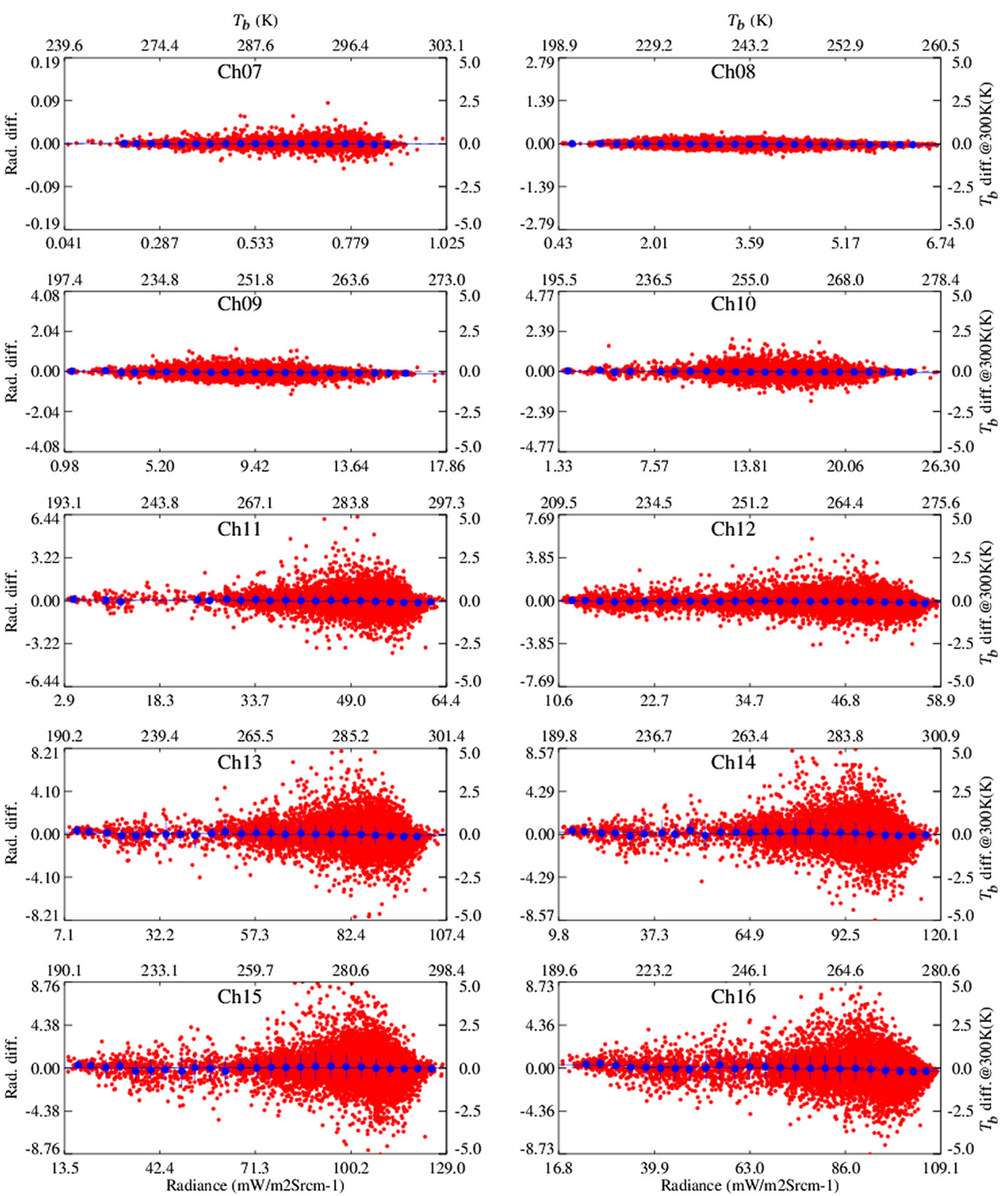

Fig. 6 Scatterplots of the G16 - IASI-B radiance versus scene radiance with the night-time homogenous scenes collected from June 1,2020, to June 30,2020. Units at the primary $x$ axis and primary $y$ axis are in radiance $\left(\mathrm{mW} / \mathrm{m}^{2} \cdot \mathrm{sr} \cdot \mathrm{cm}^{-1}\right)$, and $T_{b}(\mathrm{~K})$ is used for the second $x$ axis and $y$ axis. Each red dot represents one filtered match. The blue dot is the mean value for the matches within each radiance bin. The standard deviation of the radiance difference within each bin is plotted across the blue dot. 
As shown in Fig. 6, the uniform collocations cover a large range of radiance $/ T_{b}$ values at each IR channel. Most filtered data are scattered along warm scenes with fewer numbers at cold and very hot ones, which reflects the radiance $/ T_{b}$ value distribution in the FD Earth images. The radiance $/ T_{b}$ bias is more consistent at cold scenes than warm ones, indicating its lower uncertainty of the collocation difference at cold scenes with this method. The cold scenes are usually from the large cold clouds which are more uniform than the warm scenes which may be a mixture of different targets. The uniformity of cold clouds helps to ensure the same targets observed by the two satellites and thus less variation in the radiance $/ T_{b}$ bias. At a given $\mathrm{CoV}$, the target scene radiance and standard deviation of the same $T_{b}$ values increase with the wavelength. The increasing standard deviation of radiance leads to relatively large radiance $/ T_{b}$ bias variation at long wavelength as shown in Fig. 6.

All the IR channels seems to display a linear relationship between the radiance difference and the scene radiance over the dynamic range of the uniform scenes, confirming the detector linearity response validation results conducted in the PLPT period. ${ }^{20}$ To examine the impact of various scattering radiance $/ T_{b}$ bias at different scene radiance $/ T_{b}$ values, the collocated scene radiances of each channel are evenly binned into 25 slots. The mean radiance and radiance bias for the bins which have a minimum of 20 scenes are calculated and overplotted in Fig. 6. The $T_{b}$ and $T_{b}$ bias of each bin are available at Tables 5 and 6 for the MWIR and LWIR channels, respectively, in the Appendix. The linear slope of the binned scatterplots agrees well with the original scatterplots and no apparent nonlinear relationship can be observed at the cold or very hot scenes at both the original and the binned scatterplots. The slope of the scene radiancedependent radiance difference between the two satellites is very small at each IR channel, indicating that ABI IR radiance is in general well calibrated in a large range of ABI image radiance. Table 2 lists the slope and the uncertainty for the data in June, 2019. The $T_{b}$ bias@300 K in the linear fitting is well within the $1 \mathrm{~K} @ 300 \mathrm{~K}$ requirement for ABI radiance (Fig. 6).

The linear relationship between the radiance difference and scene radiance in Fig. 6 suggests that a linear function can be used to adjust the ABI radiance to the reference instrument calibration standard, which is one of the GSICS products. ${ }^{15}$ However, unlike the other IR channels that cover an extended dynamic range of radiance $/ T_{b}$ range of the Earth images, the minimum $T_{b}$ value for uniform Ch07 scenes is about $242 \mathrm{~K}$, even though colder scenes down to $200 \mathrm{~K}$ is common in the FD images. The $\mathrm{Ch} 07$ detector noise makes it challenging for a scene with $T_{b}$ lower than $240 \mathrm{~K}$ to pass the uniformity filtering as described in Eqs. (8) and (9). The average Ch07 detector noise equivalent differential radiance (NEdN) is about $0.002 \mathrm{~mW} / \mathrm{m}^{2} \cdot \mathrm{sr} \cdot \mathrm{cm}^{-1}$ at an extremely cold temperature. Assuming the detector noise is the major driver causing radiance variation in the target area pixels, the minimum scene radiance to pass the $\mathrm{CoV}$ threshold at $5 \%$ is thus about $0.04 \mathrm{~mW} / \mathrm{m}^{2} \cdot \mathrm{sr} \cdot \mathrm{cm}^{-1}$, which is about $240 \mathrm{~K}$ for Ch07. Yu et al. ${ }^{21}$ used collocated nonilluminated lunar images to compare the radiance difference between $\mathrm{Ch} 07$ and $\mathrm{Ch} 08$ at extreme cold samples. No apparent nonlinear difference can be observed between these two channels. Since there is a strong linear relationship between ABI and IASI-B across the $\mathrm{Ch} 08$ dynamic range, the strong linear relationship between $\mathrm{Ch} 07$ and $\mathrm{Ch} 08$ radiance over the cold lunar surface implies that the linear relation between the Ch07 ABI and IASI-B should be extended to the cold scenes lower than $240 \mathrm{~K}$.

Table 2 The slope of the linear regression between scene radiance difference and scene radiance shown in Fig 5. It is unitless.

\begin{tabular}{lclc}
\hline \hline Channel & Slope & Channel & Slope \\
\hline Ch07 & $-0.00198( \pm 0.00029)$ & Ch08 & $-0.00578( \pm 0.00020)$ \\
Ch09 & $-0.00554( \pm 0.00020)$ & Ch10 & $-0.00099( \pm 0.00024)$ \\
Ch11 & $-0.00811( \pm 0.00036)$ & Ch12 & $-0.00500( \pm 0.00025)$ \\
Ch13 & $-0.00756( \pm 0.00036)$ & Ch14 & $-0.00761( \pm 0.00036)$ \\
Ch15 & $-0.00398( \pm 0.00036)$ & Ch16 & $-0.01130( \pm 0.00035)$ \\
\hline \hline
\end{tabular}




\subsection{Calibration Accuracy and Variation}

The overall calibration accuracy for the ABI IR radiance is validated and monitored with the daily GEO-LEO intercalibration to the multiple LEO reference instruments, including IASI-B, IASI-C, SNPP/CrIS, and N20/CrIS. The daily calibration difference is calculated with the nighttime uniform collocation scenes. The spatial uniformity threshold of $\mathrm{CoV}$ value is set to $5 \%$ for each IR channel in this analysis.

Figure 7 shows the daily mean $T_{b}$ difference at $300 \mathrm{~K}$ converted from the daily mean radiance difference. Three discontinuities relevant to the major GEO and LEO GS updates can be observed in the early ABI time, including (1) the update of the quadratic term of the longwave band for IASI-B on August 2, 2017, ${ }^{10,11}$ (2) the update of the ABI SM emissivity correction lookup table (LUT) on October 19, 2017, and (3) the update of the G16 ABI LUT to accurately calculate the ICT temperature from the 12 PRTs embedded in the ICT on June 19, 2018.

In the early ABI PLT/PLPT period, it was found that the IR radiance was in general well calibrated within the specification of $1 \mathrm{~K}$ at $300 \mathrm{~K}$ equivalent scene brightness temperature. ${ }^{22,23}$ The mean $T_{b}$ bias to CrIS/IASI was in the similar magnitude as the radiance of Himawari-8 (H8) Advanced Himawari Imager (AHI) operated by Japan Meteorological Agency (JMA), ${ }^{24-26}$ which was built by the same vendor with the same optical design and launched about 2 years earlier. However, one radiometric calibration anomaly and one radiometric calibration uncertainty were reported in the early in-orbit IR data: ${ }^{27}$ (1) time series of some IR channel images display an oscillation feature that fluctuated at an interval of every $15 \mathrm{~min}$, the frequency of the
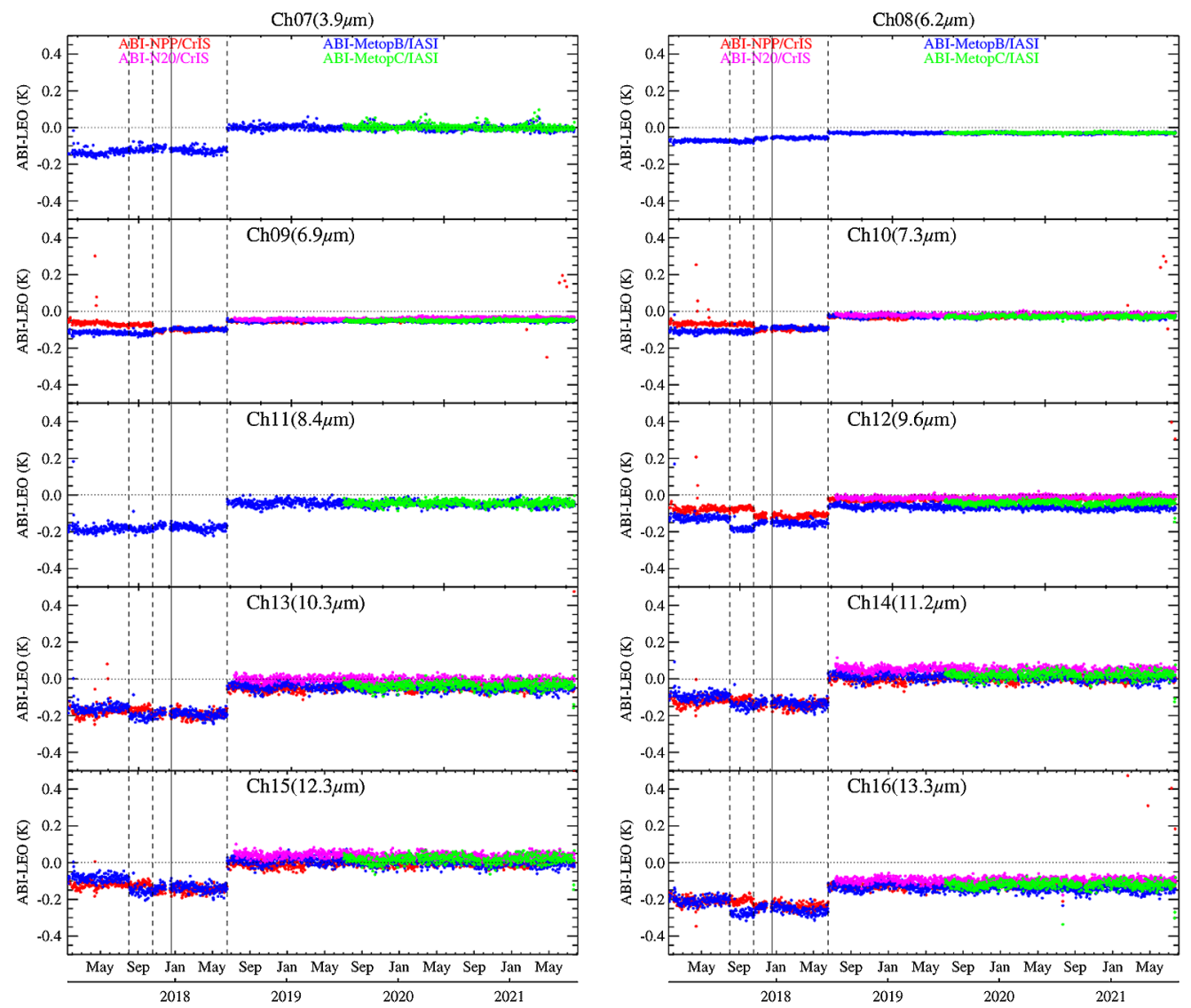

Fig. 7 Time-series of daily $T_{b}$ bias at $300 \mathrm{~K}$ between $\mathrm{G} 16$ and four LEO instrument measurements. The daily $T_{b}$ bias is calculated from the mean radiance difference between GEO and LEO and converted to $T_{b}$ bias at $300 \mathrm{~K}$. The three vertical dashed lines indicate the three GS events: August 2, 2017, for Metop-B, October 19, 2017, for G16, and June 19, 2018, for G16. The vertical solid line is the date when G16 ABI L1B data became operational (December 18, 2018). The dotted values represent ABI-SNPP/CrIS (red), G16ABI-N20/CrIS (pink), ABI-IASI-B (blue), and ABI-IASI-C (green). 
operation M3 timeline. This periodic infrared calibration anomaly (PICA) can cause $T_{b}$ variation at more than $1 \mathrm{~K}$ at cold scenes; (2) all the IR channels showed negative $T_{b}$ bias ranging from $-0.1 \mathrm{~K}$ to $-0.3 \mathrm{~K}$ to two reference LEO instruments. The cause of the PICA anomaly was later identified as the residual of the SM emissivity correction, ${ }^{28}$ and an outdated version of LUT was deployed to calculate the blackbody, resulting in about $0.2 \mathrm{~K}$ lower ICT temperature. ${ }^{29}$ The corresponding LUTs were updated at the ground system and went live on October 19, 2017, and June 19,2018, respectively. Table 3 lists the mean and standard deviation of the $T_{b}$ bias to IASI-B and SNPP/CrIS before and after the two major ABI GS updates. The mean $T_{b}$ bias of all the ABI data to both reference instruments was between $-0.3 \mathrm{~K}$ and $+0.05 \mathrm{~K}$ with uncertainty lower than $0.02 \mathrm{~K}$. After the last major update of the ABI IR calibration on June 19, 2018, the daily $T_{b}$ bias has been stable relative to all the LEO instruments at all the IR channels for more than 3 years, indicating all the five instruments have been very stable since then. The detailed impacts of the two ABI GS updates are described in the following section.

\subsubsection{Calibration variation before 19 June 2018}

(1) Impact of the SM LUT update on October 19, 2017.

As shown in Fig. 7, the $T_{b}$ difference between the ABI biases relative to IASI-B and SNPP/CrIS, inferred with the double difference between CrIS and IASI using the ABI as a calibration transfer standard, was less than $0.1 \mathrm{~K}$ at the beginning. However, when IASI-B had its longwave data processing updated on August 2, 2017, to improve the calibration accuracy, an unexpected increase in the CrIS and IASI $T_{b}$ difference was observed at ABI Ch12 to Ch16. The $T_{b}$ bias between ABI and IASI was slightly increased at these channels at the IASI-B GS update, while there was no change in the $T_{b}$ bias relative to SNPP/CrIS.

The cause of the unexpected increase of CrIS and IASI difference is due to a calibration anomaly at ABI data during this time period. In the early in-orbit time, G16 ABI radiance was processed with the prelaunch measured SM emissivity correction coefficients to correct the incidence angle-dependent absorption. The coefficients became inaccurate after the instrument was launched, resulting in calibration variations in both the EW and NS directions. The variation was more apparent in the NS direction than the EW direction, resulting in the PICA calibration anomaly, which manifested itself as a periodic oscillation of the $T_{b}$ features at some IR channels. $^{21,22}$ The new SM LUTs that were generated by the vendor using early in-orbit data were operationally implemented on October 19,2017. After this ABI update, the mean $T_{b}$ difference between CrIS and IASI was reduced from $\sim 0.1$ to $\sim 0.05 \mathrm{~K}$ (Table 3), reflecting the improvement of the ABI calibration accuracy. The change of the $T_{b}$ bias between CrIS and IASI also indicates that the accuracy of a double difference algorithm depends on the calibration uncertainty of the transfer instrument.

(2) Impact of the ABI ICT LUT update

After the SM LUT update, the cold bias relative to both CrIS and IASI remained at the IR channels, with the bias at most channels being about -0.1 to $-0.2 \mathrm{~K}$ (Table 3). The consistent cold bias strongly implied that ABI might still experience a systematic calibration error that affected the radiometric calibration accuracy of all the IR channels. An investigation of the ICT temperature calculation revealed an incorrect version of the LUT implemented to convert the PRT measurements to ICT temperature. The ABI IR radiance was calibrated to a lower ICT temperature by about $0.2 \mathrm{~K} .{ }^{27}$ The correct ICT PRT LUT was updated on June 19, 2018. After this update, the GEO-LEO $T_{b}$ bias was lifted by about 0.05 to $0.15 \mathrm{~K}$, depending on the channels. As a result, the mean $T_{b}$ bias relative to CrIS/IASI was improved within $0.05 \mathrm{~K}$ for most the IR channels except for Ch16, which has the highest $T_{b}$ bias at $-0.13 \mathrm{~K}$ (Table 3). Since the radiometric calibration accuracy is very sensitive to the SRF uncertainty at this sounding channel, the largest residual $T_{b}$ bias for Ch16 may mainly be attributed to the SRF calibration uncertainty, which was also observed in the predecessor GOES imagers. ${ }^{30,31}$

The update of the ICT LUT was conducted after G16 ABI became operational on December 18 , 2017. This GS event resulted in a sudden change in the L1b radiance and thus may lead to 


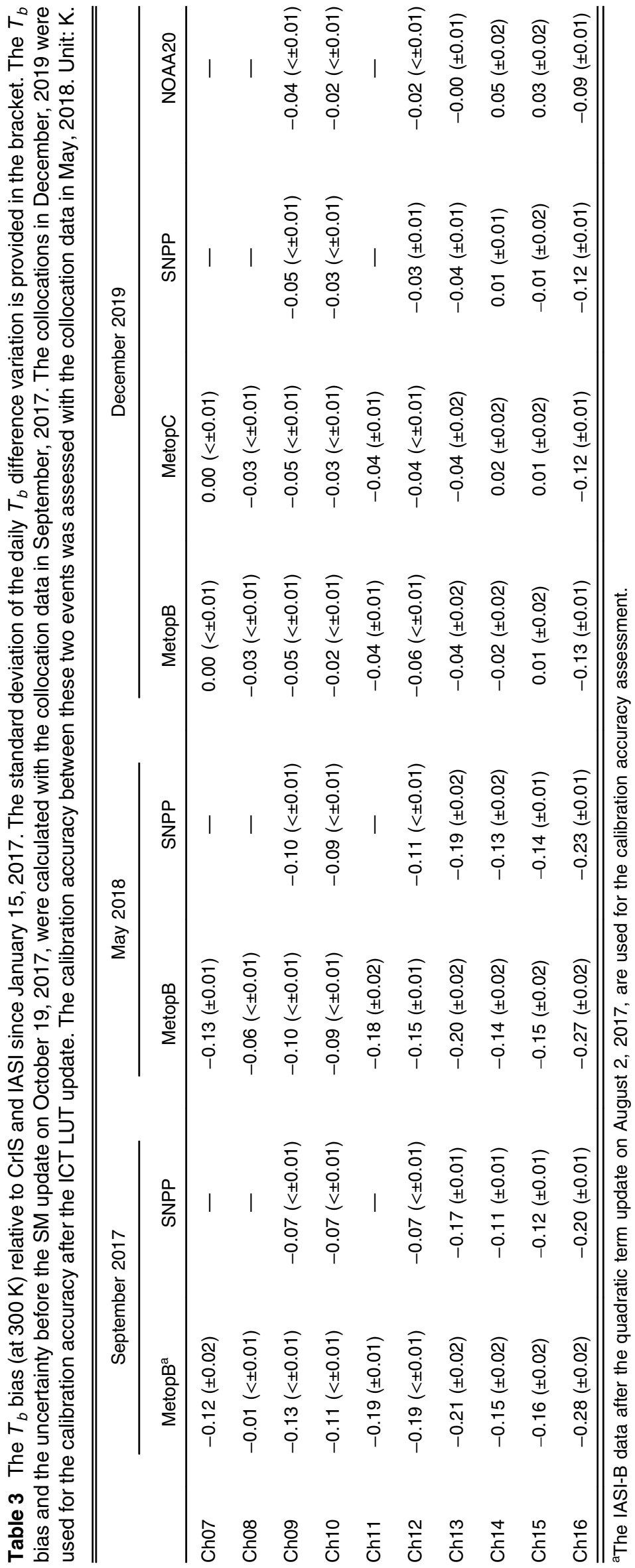


Yu et al.: Radiometric calibration accuracy and stability of GOES-16 ABI Infrared radiance

Table 4 The correction factor values in Eq. (14).

\begin{tabular}{lclc}
\hline \hline Channels & Correction factor & Channel & Correction factor \\
\hline Ch07 & 1.0072 & Ch08 & 1.0045 \\
Ch09 & 1.0040 & Ch10 & 1.0038 \\
Ch11 & 1.0033 & Ch12 & 1.0029 \\
Ch13 & 1.0027 & Ch14 & 1.0025 \\
Ch15 & 1.0023 & Ch16 & 1.0022 \\
\hline \hline
\end{tabular}

incorrect interpretation of environmental change studies. To generate the consistent L1b radiance, a semiempirical correction is provided in this study to adjust the radiance before June 19, 2018, to the calibration accuracy after this GS update. This correction is based on Eq. (1) using the ratio between the ICT radiance calculated with the two PRT LUTs. The radiance before June 19, 2018, can be corrected with the following equation:

$$
R \_ \text {new }=R \_ \text {old } * \text { Correction_factor, }
$$

where $R \_$new is the corrected radiance and $R_{-}$old is the L1B radiance before June 19, 2018. The values of Correction_factor are listed in Table 4 for each IR channel.

The result is validated with the GEO-LEO intercalibration data. The difference of the corrected radiances relative to the reference LEO instruments is compared with those operationally calibrated after the update. As shown in Fig. 8, the corrected ABI radiance displays the same $T_{b}$ bias relative to both CrIS and IASI as the ABI data calibrated with updated ICT LUT after June 19, 2019.

\subsubsection{Long-term calibration stability after June 19, 2018}

As shown in Fig. 7, no apparent seasonal variations in the $T_{b}$ bias can be observed. The longterm consistent $T_{b}$ bias to multiple reference instruments provides robust confidence in the stable ABI calibration performance. During this period, the mean $T_{b}$ bias and the standard deviation values to the four reference LEO instruments are shown in Fig. 9 and listed in Table 3. Using Metop-B as the primary reference, the bias is $<0.05 \mathrm{~K}$ for 8 of the $10 \mathrm{IR}$ channels, $-0.062 \mathrm{~K}$ for channel 12 , and $-0.13 \mathrm{~K}$ for channel 16 . Results with other instruments as reference are even better. The standard deviation of the $T_{b}$ bias is $<0.02 \mathrm{~K}$ for all IR channels. The overall accuracy is far better than the requirement of $1 \mathrm{~K}$ for the IR channels. ${ }^{19}$

As inferred from Fig. 9 and Table 3, the double difference between CrIS and IASI through ABI agrees well with the results of other studies. The mean double differences between CrIS and IASI are all well within $0.1 \mathrm{~K}$, which confirms that the four instruments are very consistent to each other with $T_{b}$ differences $<0.1 \mathrm{~K} .{ }^{9-11}$ No significant difference can be observed between the bias relative to Metop-B and Metop-C, which agrees with the analyses by Bouilon et al. ${ }^{11}$ The $T_{b}$ bias difference between the two CrIS instruments is also very small at $<0.05 \mathrm{~K}$, which echoes the direct comparison between them by Wang and Chen. ${ }^{12}$

The ABI IR radiances were also validated with different independent methods. During the G16 PLT period in spring 2017, the Scanning High-resolution Interferometer Sounder (S-HIS) was flown on NASA's ER-2 aircraft over different Earth surfaces. The intercalibration between the collocated ABI and the atmospherically corrected high-altitude S-HIS data showed that the mean $T_{b}$ difference between these two instruments was $<1 \mathrm{~K}$ at $300 \mathrm{~K}$ for all the IR channels, with the value being $<0.6 \mathrm{~K}$ during most of the study time. ${ }^{32}$ Cook et al. ${ }^{33}$ used the atmospherically corrected buoys data from clear oceans to examine the ABI calibration accuracy for ABI Ch13 and Ch16. They found that the mean $T_{b}$ difference between ABI and buoys is also well within $1 \mathrm{~K}$ at these two IR channels.

The GEO-LEO intercalibration method compares the radiance from two instruments at the TOA, allowing the direct sensor-to-sensor intercalibration or intercomparison without 

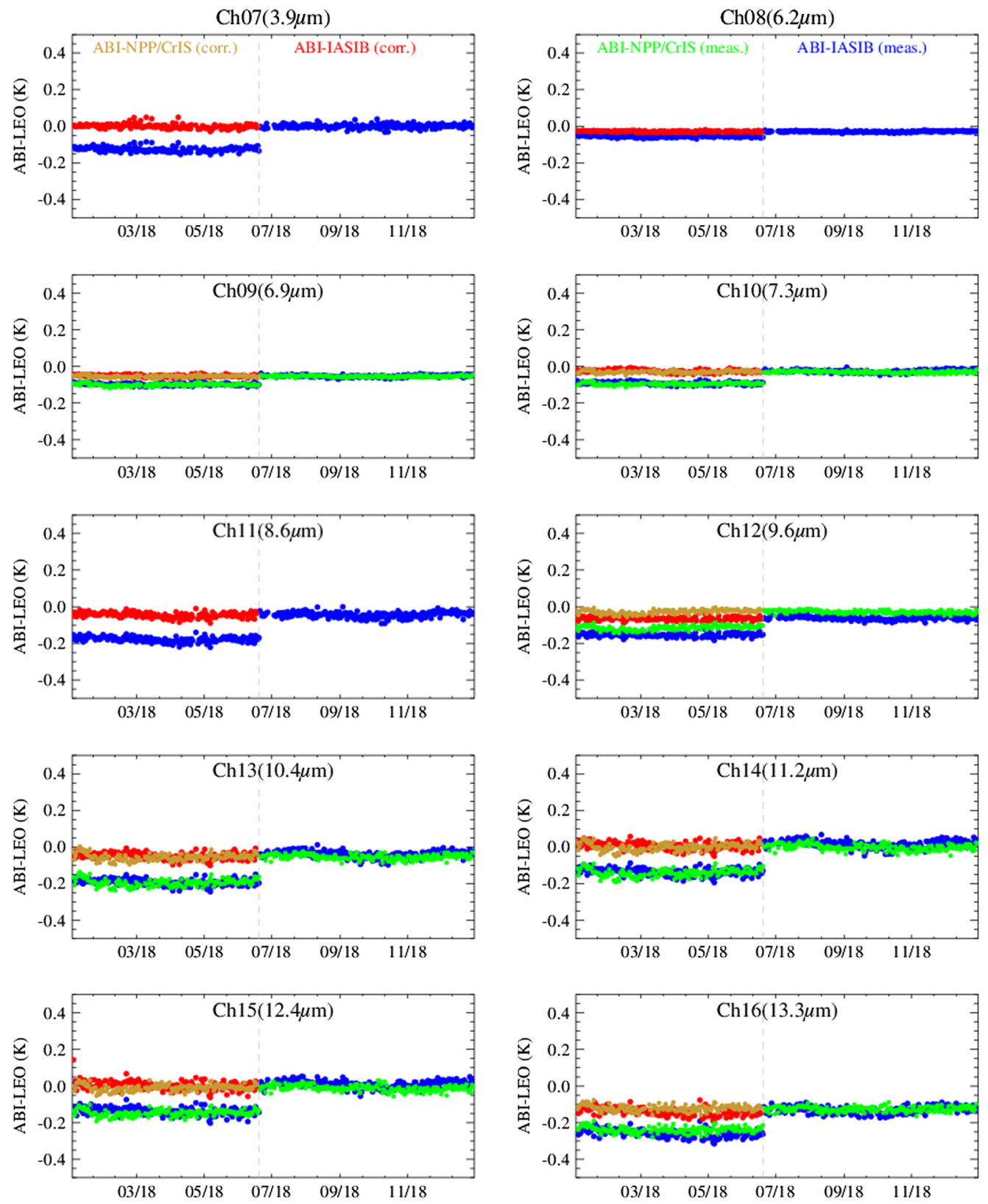

Fig. 8 Time-series of daily GEO-LEO $T_{b}$ bias in 2018. Blue (green) dots stand for the $T_{b}$ bias between operationally calibrated $\mathrm{ABI}$ and IASI-B (SNPP/CrIS). Meanwhile, the red (pink) dots represent corrected ABI data relative to Metop-B/IASI (SNPP/CrIS) before June 18, 2018.

atmospheric correction. The daily high frequency of collocation occurrence across the GEO spatial scan domain makes it possible for the routine monitoring of the ABI radiometric calibration performance. The stable and overall high accuracy of the ABI radiance, as shown from the long-term GEO-LEO intercalibration results, makes ABI a good candidate reference for the sensor-to-sensor intercalibration or intercomparison.

\subsection{Calibration Spatial Uniformity over the FOR}

The $T_{b}$ difference variations along with the latitudinal and longitudinal directions, which correspond to the NS and EW scan directions of the two SMs, are examined for possible correction residuals of the incidence angle-dependent SM absorptions. The nighttime collocations with IASI-B and SNPP/CrIS collected from August 1, 2019, to September 30, 2019, are used to assess 


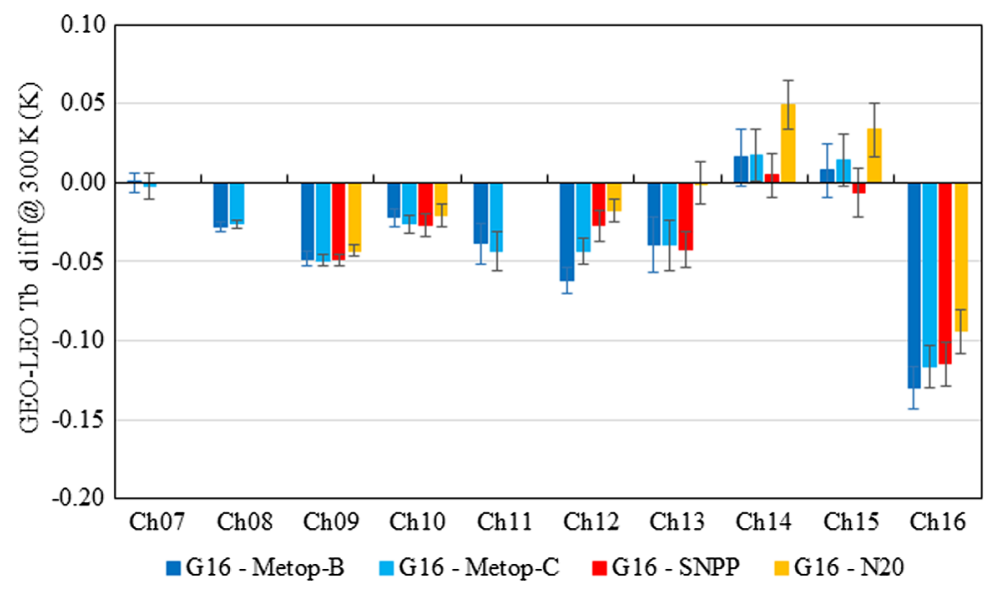

Fig. 9 Mean GEO-LEO $T_{b}$ bias and standard deviation since after the last GEO and LEO update on June 19, 2018.

the radiance spatial uniformity after the SM LUT update, and the IASI-B collocations from August 1, 2017, to September 30, 2017, are used for the data calibrated with the prelaunch measurements. At the NS direction, the homogeneous collocations were grouped into 10 latitudinal bins: eight from $40^{\circ} \mathrm{S}$ to $40^{\circ} \mathrm{N}$ latitude at a 10 -deg interval, and two beyond at each side to this range. To minimize the possible uncertainty impact from the EW SM, only the data whose longitudes were within $\pm 5 \mathrm{deg}$ from the nadir longitude are used. The same bin number and interval are applied for the longitudinal (EW) direction analysis, and only the scenes distributed within \pm 5 deg from the equator are used. The $\mathrm{CoV}$ threshold for the scene uniformity selection was set to $3 \%$ for a low uncertainty of the bias values. The geolocation of each bin is represented with the median values of the filtered collocations.

The mean and standard deviation of the calibration difference before and after the SM LUT update are shown in Figs. 10 and 11 for the NS (latitude) and EW (longitude) directions, respectively. The $T_{b}$ biases in 2019 are warmer than in 2017, due to the ABI ICT LUT update on June 2018, which increases the ABI radiance as described in the previous section. As shown in Fig. 10, before the SM LUT update, radiances within the Southern Hemisphere were warmer than those in the Northern Hemisphere, and this pattern was more apparent in the longwave channels. This was caused by the inaccurate calibration of the NS SM emissivity with the prelaunch measurement, which led to the early in-orbit PICA anomaly. After the SM LUT update on October 19, 2017, the deviation of the $T_{b}$ difference at the Southern Hemisphere was improved as shown with the bias to both CrIS and IASI data. The analysis of the Earth image radiance in this study confirms the results studied with space images that the prelaunch measurements had relatively larger uncertainty in the NS direction than at the EW direction and the in-orbit derived SM data significantly improved the ABI spatial uniformity calibration within the ABI FOR. ${ }^{23}$

The impact of the SM LUT update is not detectable in the EW direction with this method (Fig. 11), although a relatively small EW direction residual can be detected with the space image data. ${ }^{23}$ The results of this study show that the maximum $T_{b}$ variations are in general within $0.1 \mathrm{~K}$ for both EW and NS directions after the SM LUT update. The CrIS instrument passes the GEO subsatellite nadir at $13: 30 \mathrm{pm}$ local time, close to the peak scan-mirror temperature in a day (Fig. 2). The consistent mean $T_{b}$ bias to CrIS and IASI indicates that the spatial uniformity of the ABI radiance is also well maintained under the most thermal stress to the SMs.

\subsection{Calibration Stability over Local Time}

The calibration diurnal variation is examined with the IASI-B and SNPP/CrIS collocation data in July 2019. The collocations are binned with a 0.5 -h time interval. The uniformity scene selection criterion is set with $\mathrm{CoV}<3 \%$. The daytime $\mathrm{Ch} 07$ data are not analyzed to avoid the solar reflectance at this channel. To reduce the impact of directional emissivity over the land surface at the 

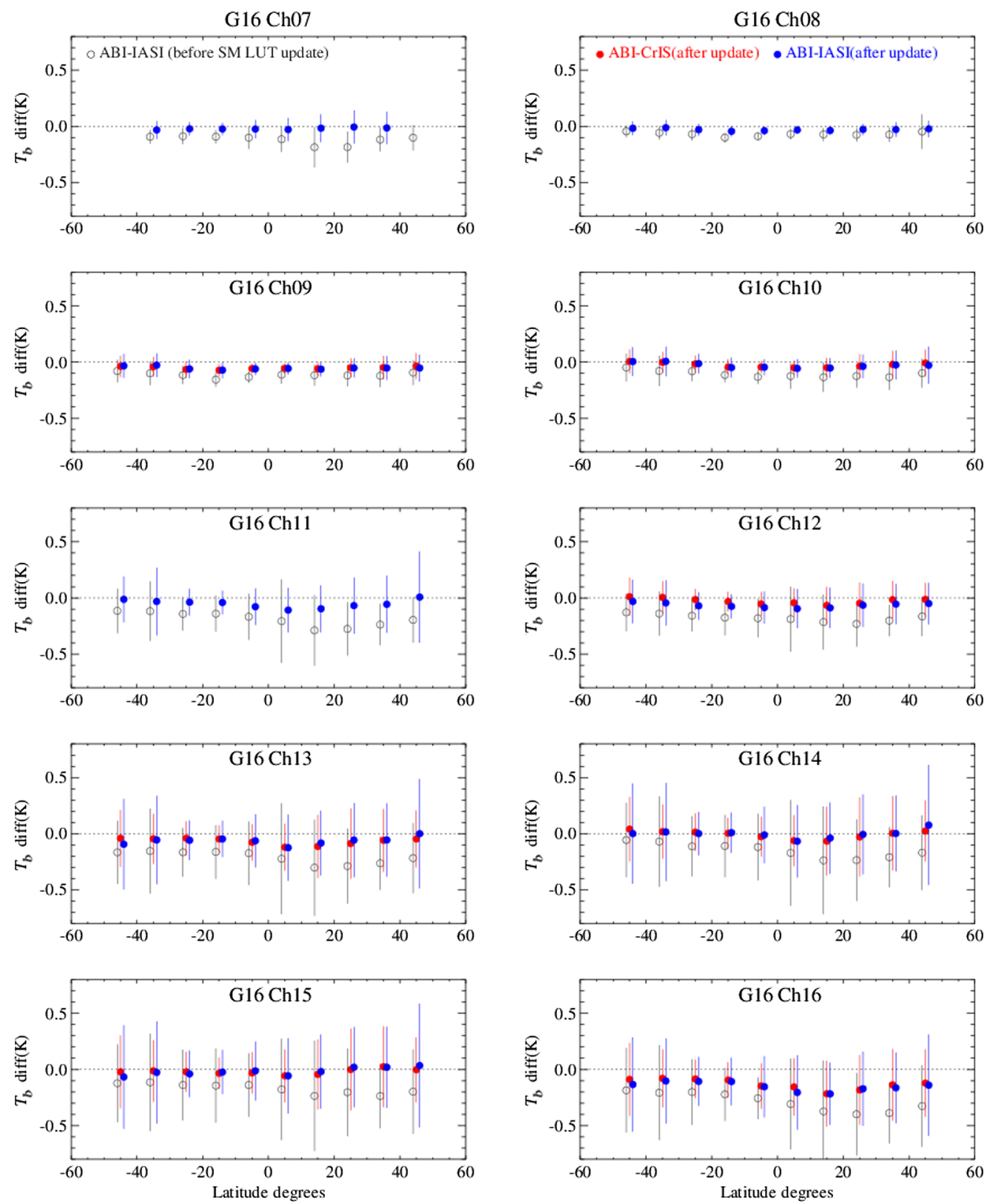

Fig. 10 Latitudinal $T_{b}$ variation relative to IASI-B and SNPP/CrIS before and after the SM LUT update on October 19, 2017. Open gray circles stand for the $T_{b}$ bias relative to IASI-B before the update, and solid blue circles and red circles are for the bias relative to IASI-B and SNPP/CrIS after the update, respectively. The vertical lines are the standard deviation of the $T_{b}$ difference for each data set in the geolocation bins. For ease of data comparison in the plots, the binned latitudes of IASI-B data in 2017 (in the open gray circles) were plotted by shifting at -3 deg, while the IASI-B data in 2019 (in the solid blue circles) were plotted by shifting at +3 deg.

window channels ${ }^{18}$ only the uniform collocations over the ocean surface are used for the daytime data analysis.

The diurnal variation of the 10 IR channels is shown in Fig. 12. The combined IASI and CrIS collocations cover most time in a day. Unlike the predecessor GOES Imagers, which had relatively large calibration uncertainty around the satellite midnight time known as the residuals of mid-night blackbody calibration correction, ${ }^{14,34}$ there is no apparent variation in the $T_{b}$ bias around the satellite midnight time for ABI. The $T_{b}$ difference relative to CrIS for both ascending and descending orbits is consistent and generally agrees well with those relative to IASI. 

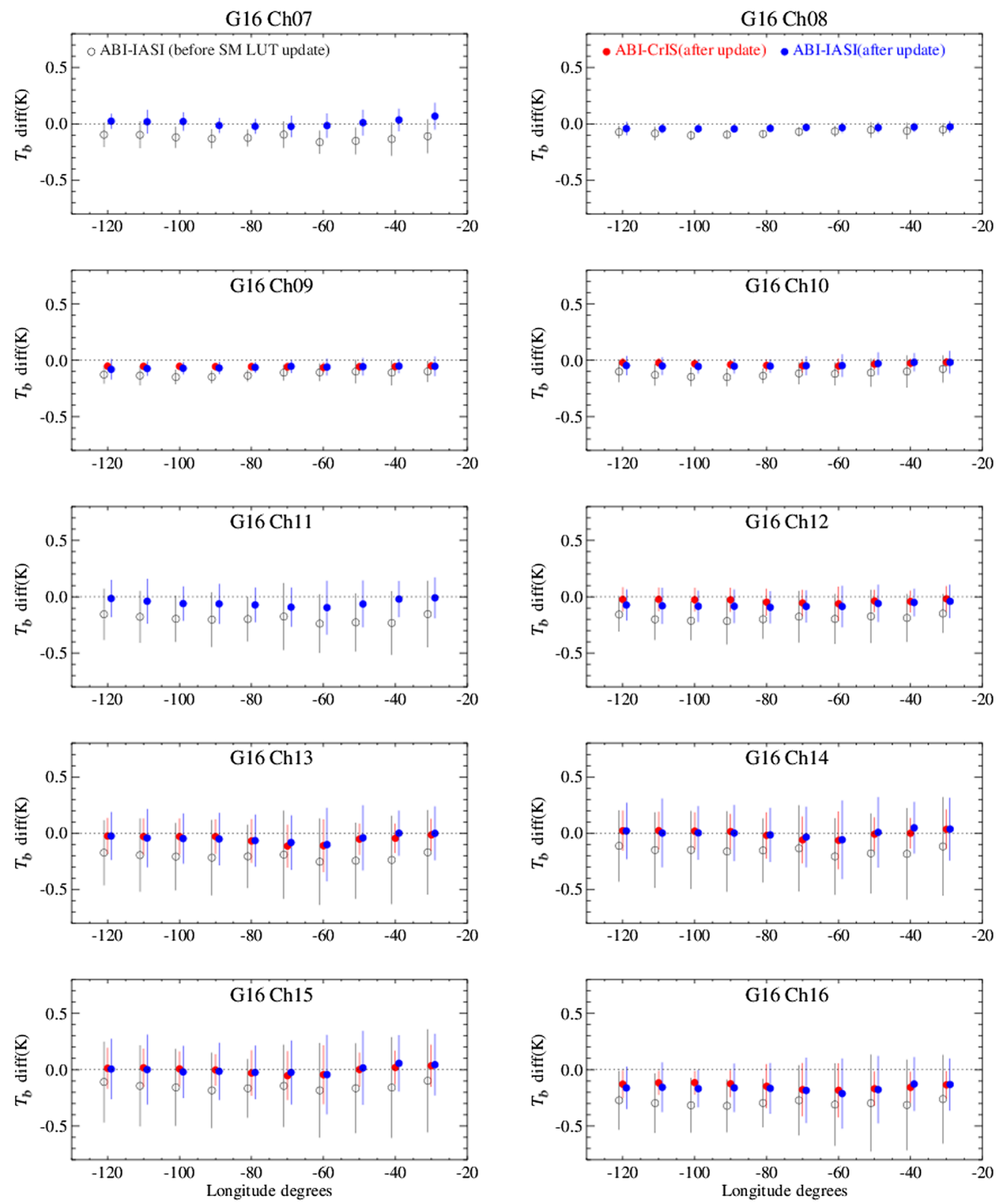

Fig. 11 Same as Fig. 7, but for the longitudinal $T_{b}$ bias between $A B I$ and the two LEO instruments. G16 drifted from $89.3^{\circ} \mathrm{W}$ to $75.2^{\circ} \mathrm{W}$ in November 2017. Accordingly, for ease of data comparison in the plots, the longitudes of the data collected between August 1, 2017, and September 30, 2017, were shifted $14.5 \mathrm{deg}$. The binned longitudes for IASI-B data in 2017 (in the open gray circles) were plotted by shifting -3 deg, while the IASI-B data in 2019 (in the solid blue circles) were plotted by shifting +3 deg.

Also, there is no detectable discontinuity in the $T_{b}$ bias around satellite noon and midnight, when the Earth limb side from which ABI spacelook measurements is taken switches. This provides an indication of accurate spatial calibration for the incidence angles near the two ends of the EW scan-mirror range. Yet before the SM LUTs were updated on October 19, 2017, a small channeldependent discontinuity of $<0.1 \mathrm{~K}$ can be observed for some IR channels. ${ }^{28}$

Certain straylight is allowed at the ABI IR images around the satellite midnight in eclipse seasons when the Sun and the satellite are at the opposite side to the Earth. During this period, solar radiation may leak into the instrument, and straylight may be present in some of the VNIR and short-wavelength IR images. ${ }^{35}$ By examining the radiance difference between every two consecutive FD images, it is found that the straylight occurs for about one and half hours at 

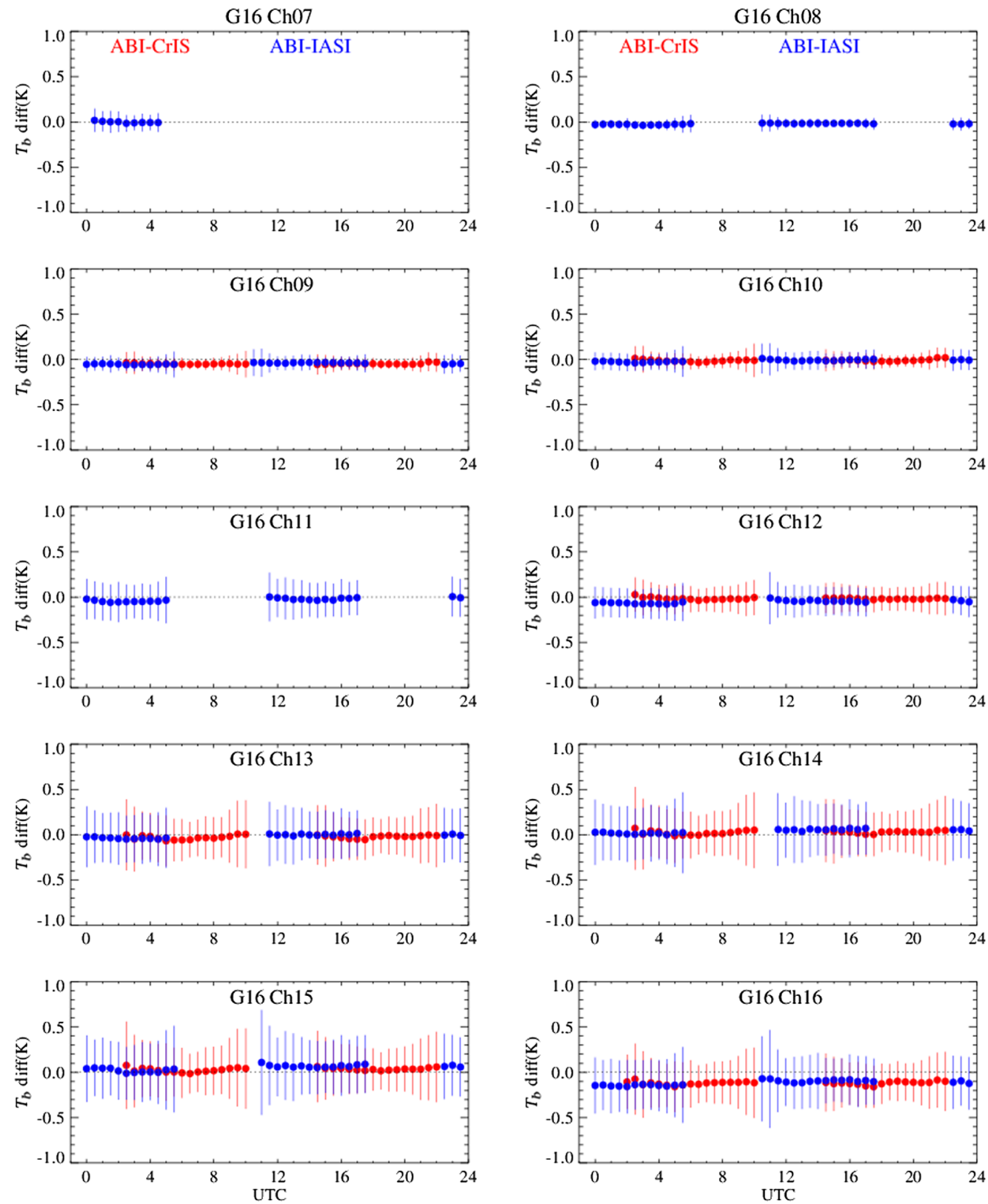

Fig. 12 Diurnal variation of the $T_{b}$ bias between ABI and CrIS/IASI at 30-min bins. The solid dots and vertical lines represent 30-min $T_{b}$ bias mean and standard deviation. Also, the G16 ABI $T_{b}$ difference relative to SNPP CrIS and Metop-B are denoted by red and blue colors.

midnight over about 3 months around the spring and fall equinox each year. There is no straylight when the Sun is behind the Earth. While the straylight location changes with time, the magnitude is well within the straylight specifications at all the IR channels. In the zone of normal performance ( $>7.5 \mathrm{deg}$ from the Sun), the impact is $<0.65 \mathrm{~K} @ 300 \mathrm{~K}$ at Ch07 and negligible at the other IR channels. ${ }^{35}$

\subsection{Calibration Variation within Timeline}

Figure 13 shows the MESO-to-MESO calibration variation for a mode 3 timeline between 22:00 UTC and 22:15 UTC on April 13, 2019. The MESO-to-MESO calibration is very stable for all the IR channels. Stability within a timeline has been similarly verified for mode 6 . As shown in Fig. 1, the MESO images are collected after both Earth scenes and star-look events, which use 

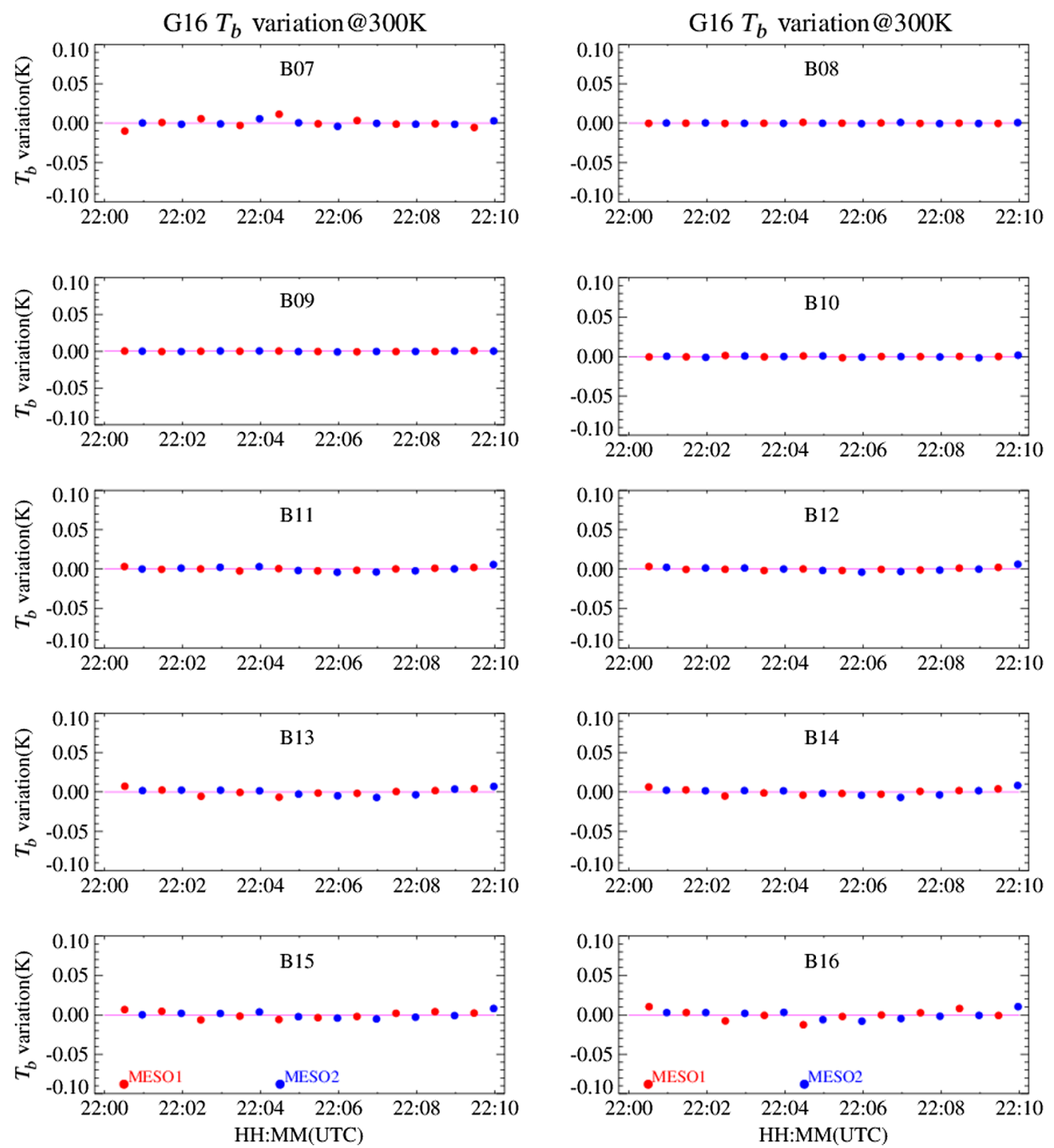

Fig. 13 The MESO-to-MESO $T_{b}$ variations with the M3 timeline on April 13, 2019.

a different integration factor from the nominal Earth scans. The consistent MESO calibration indicates that the INR calibration event does not affect the ABI radiometric calibration accuracy. As the MESO swaths are interleaved with the FD and CONUS swaths, sharing the same calibration coefficients in Eqs. (1)-(4), the stable MESO calibration also indicates that the CONUS and MESO images have the same calibration accuracy as the FD images assessed with the GEOLEO collocation data as described in Sec. 4.1.

\section{Conclusion}

G16 ABI is the first multispectral weather instrument on-board the NOAA GOES-R series satellites. It has been providing the high quality of Earth imagery for the weather forecasting and environmental change studies in the Western Hemisphere since January 2017. Using the measurements from multiple CrIS and IASI as references, it is found that the update of the scanmirror emissivity LUTs on October 19, 2017, improved the spatial calibration accuracy of the IR radiance, and the ICT PRT LUT update on June 19, 2018, improved the IR absolute calibration accuracy. After the second major GS upgrade on June 19, 2018, the ABI radiance is accurate within $0.13 \mathrm{~K}$ for $\mathrm{Ch} 16$, within $0.06 \mathrm{~K}$ for $\mathrm{Ch} 12$, and within $0.05 \mathrm{~K}$ for the other IR channels. 
The calibrated IR radiance is spatially uniform within the ABI FOR and temporally stable at varying time scales. The $T_{b}$ bias to the reference LEO instruments is absent of diurnal, seasonal, and long-term variations. The invariant radiance within various timelines indicates there is no detectable calibration difference among the FD, CONUS, and MESO images. Occasionally, some short-term calibration anomalies such as striping may occur in operation and they are noted in the calibration event log at Ref. 37. Straylight, whose impact is well within the specifications, may exist at some $\mathrm{Ch07}$ images around the midnight in eclipse seasons. Other than these shortterm disruptions, G16 ABI IR L1b radiance since June 19, 2018, is as a reliable reference for the satellite intercalibration or intercomparison.

\section{Appendix}

Tables 5 and 6 report the values of the mean brightness temperature $\left(T_{b}\right)$ and the radiance difference (converted to $T_{b}$ difference at $300 \mathrm{~K}$ ) for the bins shown in Fig. 6. Table 5 is for the MWIR channels, and Table 6 is for the LWIR channels.

Table 5 The $T_{b}$ temperature and the $T_{b}$ difference between ABI and IASI-B for the bins of the MWIR channels shown in Fig. 6 . The uncertainty of the $T_{b}$ difference (1-signa) is provided in the parenthesis. Units: K.

\begin{tabular}{|c|c|c|c|c|c|c|c|c|c|c|}
\hline & \multicolumn{2}{|c|}{ Ch07 $(3.9 \mu \mathrm{m})$} & \multicolumn{2}{|c|}{ Ch08 $(6.2 \mu \mathrm{m})$} & \multicolumn{2}{|c|}{ Ch09 $(6.9 \mu \mathrm{m})$} & \multicolumn{2}{|c|}{ Ch10 $(7.3 \mu \mathrm{m})$} & \multicolumn{2}{|c|}{ Ch11 $(8.5 \mu \mathrm{m})$} \\
\hline & $T_{b}$ & $\begin{array}{c}T_{b} \text { Diff @ } \\
300 \mathrm{~K}\end{array}$ & $T_{b}$ & $\begin{array}{c}T_{b} \text { Diff } @ \\
300 \mathrm{~K}\end{array}$ & $T_{b}$ & $\begin{array}{c}T_{b} \text { Diff @ } \\
300 \mathrm{~K}\end{array}$ & $T_{b}$ & $\begin{array}{c}T_{b} \text { Diff @ } \\
300 \mathrm{~K}\end{array}$ & $T_{b}$ & $\begin{array}{c}T_{b} \text { Diff @ } \\
300 \mathrm{~K}\end{array}$ \\
\hline Bin\#01 & - & - & - & - & 202.9 & $\begin{array}{c}0.03 \\
(0.04)\end{array}$ & 202.8 & $\begin{array}{c}0.05 \\
( \pm 0.04)\end{array}$ & 202.4 & $\begin{array}{c}0.09 \\
( \pm 0.06)\end{array}$ \\
\hline Bin\#02 & - & - & - & - & - & - & - & - & - & - \\
\hline Bin\#03 & - & - & 216.6 & $\begin{array}{c}0.01 \\
( \pm 0.06)\end{array}$ & 219.3 & $\begin{array}{c}0.07 \\
( \pm 0.10)\end{array}$ & 219.7 & $\begin{array}{c}0.09 \\
( \pm 0.12)\end{array}$ & 223.1 & $\begin{array}{c}0.04 \\
( \pm 0.30)\end{array}$ \\
\hline Bin\#04 & 266.7 & $\begin{array}{c}0.03 \\
( \pm 0.12)\end{array}$ & 221.2 & $\begin{array}{c}0.01 \\
( \pm 0.09)\end{array}$ & 224.7 & $\begin{array}{c}-0.05 \\
( \pm 0.13)\end{array}$ & 225.2 & $\begin{array}{c}-0.03 \\
( \pm 0.33)\end{array}$ & 229.9 & $\begin{array}{l}-0.06 \\
( \pm 0.31)\end{array}$ \\
\hline Bin\#05 & 269.6 & $\begin{array}{c}0.00 \\
( \pm 0.10)\end{array}$ & 224.4 & $\begin{array}{c}-0.02 \\
( \pm 0.08)\end{array}$ & 228.6 & $\begin{array}{l}-0.04 \\
( \pm 0.17)\end{array}$ & 230.1 & $\begin{array}{c}0.01 \\
( \pm 0.22)\end{array}$ & - & - \\
\hline Bin\#06 & 272.7 & $\begin{array}{c}0.01 \\
( \pm 0.09)\end{array}$ & 227.7 & $\begin{array}{c}-0.01 \\
( \pm 0.09)\end{array}$ & 233.0 & $\begin{array}{c}0.00 \\
( \pm 0.18)\end{array}$ & - & - & - & - \\
\hline Bin\#07 & 275.5 & $\begin{array}{c}0.00 \\
( \pm 0.09)\end{array}$ & 230.4 & $\begin{array}{c}0.00 \\
( \pm 0.09)\end{array}$ & 236.3 & $\begin{array}{c}-0.02 \\
( \pm 0.17)\end{array}$ & 238.1 & $\begin{array}{c}0.01 \\
( \pm 0.23)\end{array}$ & - & - \\
\hline Bin\#08 & 278.0 & $\begin{array}{c}-0.01 \\
( \pm 0.10)\end{array}$ & 233.0 & $\begin{array}{c}-0.01 \\
( \pm 0.07)\end{array}$ & 239.5 & $\begin{array}{c}0.00 \\
( \pm 0.16)\end{array}$ & 241.2 & $\begin{array}{c}0.01 \\
( \pm 0.22)\end{array}$ & - & - \\
\hline Bin\#09 & 280.2 & $\begin{array}{c}-0.01 \\
( \pm 0.09)\end{array}$ & 235.3 & $\begin{array}{c}-0.02 \\
( \pm 0.06)\end{array}$ & 242.2 & $\begin{array}{c}-0.03 \\
( \pm 0.13)\end{array}$ & 244.5 & $\begin{array}{c}0.02 \\
( \pm 0.22)\end{array}$ & 254.2 & $\begin{array}{c}0.06 \\
( \pm 0.29)\end{array}$ \\
\hline Bin\#10 & 282.3 & $\begin{array}{c}-0.01 \\
( \pm 0.10)\end{array}$ & 237.4 & $\begin{array}{c}-0.02 \\
( \pm 0.06)\end{array}$ & 244.9 & $\begin{array}{c}-0.04 \\
( \pm 0.12)\end{array}$ & 247.7 & $\begin{array}{c}0.03 \\
( \pm 0.24)\end{array}$ & 257.1 & $\begin{array}{c}0.01 \\
( \pm 0.43)\end{array}$ \\
\hline Bin\#11 & 284.3 & $\begin{array}{c}0.00 \\
( \pm 0.12)\end{array}$ & 239.5 & $\begin{array}{c}-0.03 \\
( \pm 0.06)\end{array}$ & 247.2 & $\begin{array}{c}-0.05 \\
( \pm 0.10)\end{array}$ & 250.3 & $\begin{array}{c}0.01 \\
( \pm 0.21)\end{array}$ & 261.1 & $\begin{array}{c}0.08 \\
( \pm 0.28)\end{array}$ \\
\hline Bin\#12 & 286.0 & $\begin{array}{c}0.00 \\
( \pm 0.17)\end{array}$ & 241.4 & $\begin{array}{c}-0.03 \\
( \pm 0.06)\end{array}$ & 249.6 & $\begin{array}{c}-0.05 \\
( \pm 0.10)\end{array}$ & 252.8 & $\begin{array}{c}-0.01 \\
( \pm 0.21)\end{array}$ & 264.1 & $\begin{array}{c}0.03 \\
( \pm 0.36)\end{array}$ \\
\hline Bin\#13 & 287.6 & $\begin{array}{c}0.00 \\
( \pm 0.15)\end{array}$ & 243.2 & $\begin{array}{c}-0.03 \\
( \pm 0.06)\end{array}$ & 251.8 & $\begin{array}{c}-0.06 \\
( \pm 0.10)\end{array}$ & 255.2 & $\begin{array}{c}-0.03 \\
( \pm 0.17)\end{array}$ & 267.2 & $\begin{array}{c}0.07 \\
( \pm 0.32)\end{array}$ \\
\hline
\end{tabular}


Table 5 (Continued).

\begin{tabular}{|c|c|c|c|c|c|c|c|c|c|c|}
\hline & \multicolumn{2}{|c|}{ Ch07 $(3.9 \mu \mathrm{m})$} & \multicolumn{2}{|c|}{ Ch08 $(6.2 \mu \mathrm{m})$} & \multicolumn{2}{|c|}{ Ch09 $(6.9 \mu \mathrm{m})$} & \multicolumn{2}{|c|}{ Ch10 $(7.3 \mu \mathrm{m})$} & \multicolumn{2}{|c|}{ Ch11 $(8.5 \mu \mathrm{m})$} \\
\hline & $T_{b}$ & $\begin{array}{c}T_{b} \text { Diff @ } \\
300 \mathrm{~K}\end{array}$ & $T_{b}$ & $\begin{array}{c}T_{b} \text { Diff @ } \\
300 \mathrm{~K}\end{array}$ & $T_{b}$ & $\begin{array}{c}T_{b} \text { Diff @ } \\
300 \mathrm{~K}\end{array}$ & $T_{b}$ & $\begin{array}{c}T_{b} \text { Diff @ } \\
300 \mathrm{~K}\end{array}$ & $T_{b}$ & $\begin{array}{c}T_{b} \text { Diff @ } \\
300 \mathrm{~K} \\
\end{array}$ \\
\hline Bin\#14 & 289.2 & $\begin{array}{c}0.00 \\
( \pm 0.15)\end{array}$ & 244.9 & $\begin{array}{c}-0.03 \\
( \pm 0.06)\end{array}$ & 253.8 & $\begin{array}{c}-0.06 \\
( \pm 0.10)\end{array}$ & 257.4 & $\begin{array}{c}-0.04 \\
( \pm 0.15)\end{array}$ & 270.0 & $\begin{array}{c}-0.01 \\
( \pm 0.30)\end{array}$ \\
\hline Bin\#15 & 290.7 & $\begin{array}{c}0.01 \\
( \pm 0.14)\end{array}$ & 246.6 & $\begin{array}{c}-0.04 \\
( \pm 0.06)\end{array}$ & 255.9 & $\begin{array}{c}-0.06 \\
( \pm 0.11)\end{array}$ & 259.5 & $\begin{array}{c}-0.04 \\
( \pm 0.13)\end{array}$ & 272.9 & $\begin{array}{c}0.03 \\
( \pm 0.42)\end{array}$ \\
\hline Bin\#16 & 292.1 & $\begin{array}{c}0.01 \\
( \pm 0.15)\end{array}$ & 248.1 & $\begin{array}{c}-0.04 \\
( \pm 0.06)\end{array}$ & 257.8 & $\begin{array}{l}-0.06 \\
( \pm 0.10)\end{array}$ & 261.6 & $\begin{array}{c}-0.04 \\
( \pm 0.13)\end{array}$ & 275.6 & $\begin{array}{c}0.01 \\
( \pm 0.43)\end{array}$ \\
\hline Bin\#17 & 293.4 & $\begin{array}{c}-0.01 \\
( \pm 0.14)\end{array}$ & 249.6 & $\begin{array}{c}-0.04 \\
( \pm 0.06)\end{array}$ & 259.5 & $\begin{array}{c}-0.07 \\
( \pm 0.09)\end{array}$ & 263.6 & $\begin{array}{c}-0.04 \\
( \pm 0.13)\end{array}$ & 278.1 & $\begin{array}{c}-0.01 \\
( \pm 0.36)\end{array}$ \\
\hline Bin\#18 & 294.7 & $\begin{array}{c}-0.01 \\
( \pm 0.14)\end{array}$ & 251.0 & $\begin{array}{c}-0.04 \\
( \pm 0.06)\end{array}$ & 261.3 & $\begin{array}{c}-0.07 \\
( \pm 0.09)\end{array}$ & 265.5 & $\begin{array}{c}-0.03 \\
( \pm 0.12)\end{array}$ & 280.7 & $\begin{array}{c}0.02 \\
( \pm 0.38)\end{array}$ \\
\hline Bin\#19 & 295.9 & $\begin{array}{c}0.01 \\
( \pm 0.19)\end{array}$ & 252.4 & $\begin{array}{c}-0.04 \\
( \pm 0.05)\end{array}$ & 262.9 & $\begin{array}{c}-0.08 \\
( \pm 0.08)\end{array}$ & 267.3 & $\begin{array}{c}-0.03 \\
( \pm 0.11)\end{array}$ & 283.0 & $\begin{array}{c}0.00 \\
( \pm 0.35)\end{array}$ \\
\hline Bin\#20 & 297.1 & $\begin{array}{c}-0.02 \\
( \pm 0.18)\end{array}$ & 253.7 & $\begin{array}{c}-0.05 \\
( \pm 0.05)\end{array}$ & 264.5 & $\begin{array}{c}-0.09 \\
( \pm 0.10)\end{array}$ & 269.1 & $\begin{array}{c}-0.03 \\
( \pm 0.09)\end{array}$ & 285.3 & $\begin{array}{c}-0.01 \\
( \pm 0.37)\end{array}$ \\
\hline Bin\#21 & 298.3 & $\begin{array}{c}-0.04 \\
( \pm 0.13)\end{array}$ & 255.0 & $\begin{array}{c}-0.05 \\
( \pm 0.09)\end{array}$ & 266.2 & $\begin{array}{c}-0.09 \\
( \pm 0.09)\end{array}$ & 270.8 & $\begin{array}{c}-0.03 \\
( \pm 0.09)\end{array}$ & 287.5 & $\begin{array}{c}-0.05 \\
( \pm 0.36)\end{array}$ \\
\hline Bin\#22 & 299.1 & $\begin{array}{c}-0.05 \\
( \pm 0.12)\end{array}$ & 256.2 & $\begin{array}{c}-0.07 \\
( \pm 0.05)\end{array}$ & 267.6 & $\begin{array}{c}-0.09 \\
( \pm 0.06)\end{array}$ & 272.3 & $\begin{array}{c}-0.02 \\
( \pm 0.06)\end{array}$ & 289.7 & $\begin{array}{c}-0.08 \\
( \pm 0.27)\end{array}$ \\
\hline Bin\#23 & - & - & 257.5 & $\begin{array}{c}-0.06 \\
( \pm 0.06)\end{array}$ & 269.2 & $\begin{array}{c}-0.10 \\
( \pm 0.05)\end{array}$ & 274.0 & $\begin{array}{c}-0.03 \\
( \pm 0.07)\end{array}$ & 291.6 & $\begin{array}{c}-0.10 \\
( \pm 0.23)\end{array}$ \\
\hline Bin\#24 & - & - & 258.5 & $\begin{array}{c}-0.06 \\
( \pm 0.05)\end{array}$ & - & - & 275.3 & $\begin{array}{c}-0.02 \\
( \pm 0.03)\end{array}$ & 293.5 & $\begin{array}{c}-0.12 \\
( \pm 0.18)\end{array}$ \\
\hline Bin\#25 & - & - & - & - & - & - & - & - & 295.2 & $\begin{array}{c}-0.07 \\
( \pm 0.14)\end{array}$ \\
\hline
\end{tabular}

Table 6 The $T_{b}$ temperature and the $T_{b}$ difference between ABI and IASI-B for the bins of the LWIR channels shown in Fig. 6 . The uncertainty of the $T_{b}$ difference (1-signa) is provided in the parenthesis. Units: K.

\begin{tabular}{|c|c|c|c|c|c|c|c|c|c|c|}
\hline & \multicolumn{2}{|c|}{ Ch12 $(9.6 \mu \mathrm{m})$} & \multicolumn{2}{|c|}{ Ch13 $(10.3 \mu \mathrm{m})$} & \multicolumn{2}{|c|}{ Ch14 $(11.2 \mu \mathrm{m})$} & \multicolumn{2}{|c|}{ Ch15 $(12.3 \mu \mathrm{m})$} & \multicolumn{2}{|c|}{ Ch16 $(13.3 \mu \mathrm{m})$} \\
\hline & $T_{b}$ & $\begin{array}{c}T_{b} \text { Diff @ } \\
300 \mathrm{~K}\end{array}$ & $T_{b}$ & $\begin{array}{c}T_{b} \text { Diff @ } \\
300 \mathrm{~K}\end{array}$ & $T_{b}$ & $\begin{array}{c}T_{b} \text { Diff @ } \\
300 \mathrm{~K}\end{array}$ & $T_{b}$ & $\begin{array}{c}T_{b} \text { Diff @ } \\
300 \mathrm{~K}\end{array}$ & $T_{b}$ & $\begin{array}{c}T_{b} \text { Diff @ } \\
300 \mathrm{~K}\end{array}$ \\
\hline Bin\#01 & 213.9 & $\begin{array}{c}0.01 \\
( \pm 0.09)\end{array}$ & 200.5 & $\begin{array}{c}0.23 \\
( \pm 0.11)\end{array}$ & 199.4 & $\begin{array}{c}0.21 \\
( \pm 0.13)\end{array}$ & 198.7 & $\begin{array}{c}0.18 \\
( \pm 0.17)\end{array}$ & - & - \\
\hline Bin\#02 & 217.8 & $\begin{array}{c}0.01 \\
( \pm 0.18)\end{array}$ & 208.4 & $\begin{array}{c}0.16 \\
( \pm 0.17)\end{array}$ & 206.9 & $\begin{array}{c}0.18 \\
( \pm 0.25)\end{array}$ & 205.3 & $\begin{array}{c}0.15 \\
( \pm 0.21)\end{array}$ & 201.2 & $\begin{array}{c}0.22 \\
( \pm 0.18)\end{array}$ \\
\hline Bin\#03 & 221.9 & $\begin{array}{c}-0.03 \\
( \pm 0.24)\end{array}$ & 218.3 & $\begin{array}{c}0.10 \\
( \pm 0.32)\end{array}$ & 215.8 & $\begin{array}{c}0.08 \\
( \pm 0.37)\end{array}$ & 212.5 & $\begin{array}{c}0.03 \\
( \pm 0.48)\end{array}$ & 206.3 & $\begin{array}{c}0.28 \\
( \pm 0.29)\end{array}$ \\
\hline Bin\#04 & 225.6 & $\begin{array}{c}-0.07 \\
( \pm 0.30)\end{array}$ & 225.0 & $\begin{array}{c}-0.07 \\
( \pm 0.51)\end{array}$ & 221.9 & $\begin{array}{c}0.07 \\
( \pm 0.49)\end{array}$ & 218.5 & $\begin{array}{c}0.12 \\
( \pm 0.46)\end{array}$ & 211.7 & $\begin{array}{c}0.15 \\
( \pm 0.48)\end{array}$ \\
\hline Bin\#05 & 229.2 & $\begin{array}{c}-0.05 \\
( \pm 0.31)\end{array}$ & 230.8 & $\begin{array}{c}-0.10 \\
( \pm 0.47)\end{array}$ & 227.9 & $\begin{array}{c}-0.10 \\
( \pm 0.54)\end{array}$ & 224.6 & $\begin{array}{c}-0.18 \\
( \pm 0.59)\end{array}$ & 216.4 & $\begin{array}{c}0.04 \\
( \pm 0.45)\end{array}$ \\
\hline
\end{tabular}


Table 6 (Continued).

\begin{tabular}{|c|c|c|c|c|c|c|c|c|c|c|}
\hline & \multicolumn{2}{|c|}{ Ch12 $(9.6 \mu \mathrm{m})$} & \multicolumn{2}{|c|}{ Ch13 $(10.3 \mu \mathrm{m})$} & \multicolumn{2}{|c|}{ Ch14 $(11.2 \mu \mathrm{m})$} & \multicolumn{2}{|c|}{ Ch15 $(12.3 \mu \mathrm{m})$} & \multicolumn{2}{|c|}{ Ch16 $(13.3 \mu \mathrm{m})$} \\
\hline & $T_{b}$ & $\begin{array}{c}T_{b} \text { Diff @ } \\
300 \mathrm{~K}\end{array}$ & $T_{b}$ & $\begin{array}{c}T_{b} \text { Diff @ } \\
300 \mathrm{~K}\end{array}$ & $T_{b}$ & $\begin{array}{c}T_{b} \text { Diff @ } \\
300 \mathrm{~K}\end{array}$ & $T_{b}$ & $\begin{array}{c}T_{b} \text { Diff @ } \\
300 \mathrm{~K}\end{array}$ & $T_{b}$ & $\begin{array}{c}T_{b} \text { Diff @ } \\
300 \mathrm{~K} \\
\end{array}$ \\
\hline Bin\#06 & 232.5 & $\begin{array}{c}-0.05 \\
( \pm 0.35)\end{array}$ & 235.7 & $\begin{array}{c}0.00 \\
( \pm 0.55)\end{array}$ & 233.2 & $\begin{array}{c}0.02 \\
( \pm 0.60)\end{array}$ & 230.0 & $\begin{array}{c}-0.11 \\
( \pm 0.61)\end{array}$ & 220.8 & $\begin{array}{c}0.04 \\
( \pm 0.68)\end{array}$ \\
\hline Bin\#07 & 235.7 & $\begin{array}{c}-0.04 \\
( \pm 0.33)\end{array}$ & 241.4 & $\begin{array}{c}0.01 \\
( \pm 0.73)\end{array}$ & 239.1 & $\begin{array}{c}0.08 \\
( \pm 0.75)\end{array}$ & 234.7 & $\begin{array}{c}-0.08 \\
( \pm 0.66)\end{array}$ & 224.9 & $\begin{array}{l}-0.01 \\
( \pm 0.62)\end{array}$ \\
\hline Bin\#08 & 238.5 & $\begin{array}{c}-0.03 \\
( \pm 0.32)\end{array}$ & 245.8 & $\begin{array}{c}0.01 \\
( \pm 0.40)\end{array}$ & 243.2 & $\begin{array}{c}0.02 \\
( \pm 0.51)\end{array}$ & 240.0 & $\begin{array}{c}-0.19 \\
( \pm 0.88)\end{array}$ & 228.8 & $\begin{array}{c}-0.02 \\
( \pm 0.63)\end{array}$ \\
\hline Bin\#09 & 241.3 & $\begin{array}{c}-0.03 \\
( \pm 0.27)\end{array}$ & 250.1 & $\begin{array}{c}-0.06 \\
( \pm 0.74)\end{array}$ & 247.8 & $\begin{array}{c}0.25 \\
( \pm 0.65)\end{array}$ & 243.8 & $\begin{array}{c}0.03 \\
( \pm 0.72)\end{array}$ & 232.3 & $\begin{array}{c}-0.08 \\
( \pm 0.62)\end{array}$ \\
\hline Bin\#10 & 244.0 & $\begin{array}{c}-0.04 \\
( \pm 0.29)\end{array}$ & 254.8 & $\begin{array}{c}0.05 \\
( \pm 0.50)\end{array}$ & 252.0 & $\begin{array}{c}-0.07 \\
( \pm 0.74)\end{array}$ & 248.1 & $\begin{array}{c}-0.02 \\
( \pm 0.77)\end{array}$ & 236.2 & $\begin{array}{c}0.01 \\
( \pm 0.85)\end{array}$ \\
\hline Bin\#11 & 246.5 & $\begin{array}{c}-0.05 \\
( \pm 0.27)\end{array}$ & 258.3 & $\begin{array}{c}0.16 \\
( \pm 0.60)\end{array}$ & 256.1 & $\begin{array}{c}0.12 \\
( \pm 0.46)\end{array}$ & 252.2 & $\begin{array}{l}-0.19 \\
( \pm 0.66)\end{array}$ & 239.5 & $\begin{array}{c}0.17 \\
( \pm 0.89)\end{array}$ \\
\hline Bin\#12 & 248.9 & $\begin{array}{c}-0.03 \\
( \pm 0.33)\end{array}$ & 262.3 & $\begin{array}{c}0.04 \\
( \pm 0.46)\end{array}$ & 260.0 & $\begin{array}{c}0.12 \\
( \pm 0.50)\end{array}$ & 256.1 & $\begin{array}{c}0.06 \\
( \pm 0.47)\end{array}$ & 242.9 & $\begin{array}{l}-0.03 \\
( \pm 0.70)\end{array}$ \\
\hline Bin\#13 & 251.3 & $\begin{array}{c}-0.02 \\
( \pm 0.30)\end{array}$ & 265.8 & $\begin{array}{c}0.08 \\
( \pm 0.48)\end{array}$ & 263.5 & $\begin{array}{c}0.09 \\
( \pm 0.52)\end{array}$ & 260.0 & $\begin{array}{c}0.02 \\
( \pm 0.55)\end{array}$ & 246.1 & $\begin{array}{c}0.08 \\
( \pm 0.77)\end{array}$ \\
\hline Bin\#14 & 253.5 & $\begin{array}{c}-0.02 \\
( \pm 0.26)\end{array}$ & 269.0 & $\begin{array}{c}0.06 \\
( \pm 0.49)\end{array}$ & 267.0 & $\begin{array}{c}0.16 \\
( \pm 0.54)\end{array}$ & 263.4 & $\begin{array}{c}0.05 \\
( \pm 0.63)\end{array}$ & 249.3 & $\begin{array}{c}0.08 \\
( \pm 0.70)\end{array}$ \\
\hline Bin\#15 & 255.7 & $\begin{array}{c}-0.03 \\
( \pm 0.29)\end{array}$ & 272.2 & $\begin{array}{c}0.00 \\
( \pm 0.48)\end{array}$ & 270.2 & $\begin{array}{c}0.09 \\
( \pm 0.55)\end{array}$ & 266.8 & $\begin{array}{c}0.03 \\
( \pm 0.63)\end{array}$ & 252.3 & $\begin{array}{c}0.03 \\
( \pm 0.59)\end{array}$ \\
\hline Bin\#16 & 257.8 & $\begin{array}{c}-0.03 \\
( \pm 0.30)\end{array}$ & 275.6 & $\begin{array}{c}0.06 \\
( \pm 0.63)\end{array}$ & 273.5 & $\begin{array}{c}0.13 \\
( \pm 0.71)\end{array}$ & 270.0 & $\begin{array}{c}0.06 \\
( \pm 0.72)\end{array}$ & 255.4 & $\begin{array}{c}0.02 \\
( \pm 0.72)\end{array}$ \\
\hline Bin\#17 & 259.9 & $\begin{array}{c}-0.04 \\
( \pm 0.29)\end{array}$ & 278.5 & $\begin{array}{c}0.01 \\
( \pm 0.55)\end{array}$ & 276.8 & $\begin{array}{c}0.17 \\
( \pm 0.68)\end{array}$ & 273.3 & $\begin{array}{c}0.10 \\
( \pm 0.82)\end{array}$ & 258.2 & $\begin{array}{c}-0.02 \\
( \pm 0.66)\end{array}$ \\
\hline Bin\#18 & 261.8 & $\begin{array}{c}-0.04 \\
( \pm 0.29)\end{array}$ & 281.4 & $\begin{array}{c}0.03 \\
( \pm 0.51)\end{array}$ & 279.9 & $\begin{array}{c}0.09 \\
( \pm 0.61)\end{array}$ & 276.5 & $\begin{array}{c}0.11 \\
( \pm 0.76)\end{array}$ & 261.0 & $\begin{array}{c}0.00 \\
( \pm 0.69)\end{array}$ \\
\hline Bin\#19 & 263.8 & $\begin{array}{c}-0.05 \\
( \pm 0.27)\end{array}$ & 284.2 & $\begin{array}{c}0.04 \\
( \pm 0.52)\end{array}$ & 282.8 & $\begin{array}{c}0.11 \\
( \pm 0.57)\end{array}$ & 279.6 & $\begin{array}{c}0.09 \\
( \pm 0.69)\end{array}$ & 263.6 & $\begin{array}{c}-0.04 \\
( \pm 0.75)\end{array}$ \\
\hline Bin\#20 & 265.6 & $\begin{array}{c}-0.05 \\
( \pm 0.27)\end{array}$ & 287.0 & $\begin{array}{c}-0.01 \\
( \pm 0.52)\end{array}$ & 285.7 & $\begin{array}{c}0.08 \\
( \pm 0.59)\end{array}$ & 282.6 & $\begin{array}{c}0.07 \\
( \pm 0.63)\end{array}$ & 266.4 & $\begin{array}{c}-0.01 \\
( \pm 0.74)\end{array}$ \\
\hline Bin\#21 & 267.5 & $\begin{array}{c}-0.05 \\
( \pm 0.28)\end{array}$ & 289.5 & $\begin{array}{c}-0.05 \\
( \pm 0.51)\end{array}$ & 288.4 & $\begin{array}{c}0.01 \\
( \pm 0.54)\end{array}$ & 285.5 & $\begin{array}{c}0.01 \\
( \pm 0.56)\end{array}$ & 269.0 & $\begin{array}{l}-0.07 \\
( \pm 0.60)\end{array}$ \\
\hline Bin\#22 & 269.2 & $\begin{array}{l}-0.09 \\
( \pm 0.24)\end{array}$ & 292.2 & $\begin{array}{c}-0.09 \\
( \pm 0.37)\end{array}$ & 291.2 & $\begin{array}{c}-0.05 \\
( \pm 0.42)\end{array}$ & 288.2 & $\begin{array}{l}-0.05 \\
( \pm 0.42)\end{array}$ & 271.5 & $\begin{array}{l}-0.15 \\
( \pm 0.48)\end{array}$ \\
\hline Bin\#23 & 270.9 & $\begin{array}{l}-0.10 \\
( \pm 0.21)\end{array}$ & 294.5 & $\begin{array}{c}-0.12 \\
( \pm 0.29)\end{array}$ & 293.6 & $\begin{array}{l}-0.07 \\
( \pm 0.31)\end{array}$ & 290.8 & $\begin{array}{c}-0.04 \\
( \pm 0.30)\end{array}$ & 274.0 & $\begin{array}{l}-0.20 \\
( \pm 0.32)\end{array}$ \\
\hline Bin\#24 & 272.6 & $\begin{array}{c}-0.13 \\
( \pm 0.17)\end{array}$ & 296.7 & $\begin{array}{c}-0.12 \\
( \pm 0.21)\end{array}$ & 296.0 & $\begin{array}{c}-0.07 \\
( \pm 0.24)\end{array}$ & 293.2 & $\begin{array}{c}-0.03 \\
( \pm 0.24)\end{array}$ & 276.2 & $\begin{array}{c}-0.21 \\
( \pm 0.23)\end{array}$ \\
\hline Bin\#25 & 273.8 & $\begin{array}{c}-0.15 \\
( \pm 0.13)\end{array}$ & - & - & 298.4 & $\begin{array}{c}-0.03 \\
( \pm 0.19)\end{array}$ & 295.7 & $\begin{array}{c}-0.04 \\
( \pm 0.17)\end{array}$ & 278.2 & $\begin{array}{l}-0.20 \\
( \pm 0.14)\end{array}$ \\
\hline
\end{tabular}




\section{Acknowledgments}

This study was funded by the NOAA GOES-R Program through Grant Nos. NA19NES432002 and NA14NES432003 (Cooperative Institute for Satellite Earth System Studies - CISESS) at the University of Maryland/ESSIC. The authors would like to thank NOAA GOES-R Program Office, GOES-R Product Readiness and Operations (PRO) Team, GOES-R Data Operations Support Team (DOST), NOAA STAR Algorithm Working Group (AWG) Team, and MIT/ Lincoln Laboratory for help and support with the ABI calibration and validation work, and JMA for sharing the AHI data through an agreement between NOAA and JMA to cooperate on respective advanced geostationary meteorological satellites. Dr. Aaron Pearlman and Mr. Frank Padula were consulted for ABI prelaunch calibration; Dr. Boryana Efromova contributed to early G16 ABI in-orbit calibration; Dr. Vladimir Kondratovich advised on G16 ABI INR calibration performance; Mr. Chad Gravelle discovered the PICA phenomenon; and Dr. Peng $\mathrm{Yu}$ helped with the ABI land surface mask data. The scientific results and conclusions, as well as any views or opinions expressed herein, are those of the authors and do not necessarily reflect those of NOAA or the Department of Commerce.

\section{References}

1. T. Schmit et al., "A closer look at the ABI on the GOES-R Series," Bull. Am. Meteorol. Soc. 98, 681-698 (2017).

2. X. Wu, et al., "GOES-R ABI beta, provisional and full validation readiness, implementation and management plan (RIMP)," GOES-R Ground Segment/Code416, 2016, https://goessp .ndc.nasa.gov.

3. S. Kalluri et al., "From photons to pixels: processing data from advanced baseline imager," Remote Sens. 10, 177 (2018).

4. GOES-R Series Program, "GOES-R series product definition and users' guide," 2018, https://www.goes-r.gov/products/docs.

5. M. Weinreb et al., "Operational calibration of geostationary operational environmental Satellite-8 and -9 imagers and sounders," Appl. Opt. 36(27) 6895-6904 (1997).

6. R. Dalta et al., "Comparison of the calibration algorithms and SI traceability of MODIS, VIIRS, GOES, and GOES-R ABI sensors," Remote Sens. 8, 126 (2016).

7. D. Tobin et al., "Suomi-NPP CrIS radiometric calibration uncertainty," J. Geophys. Res. 118(18), 10589-10600 (2013).

8. Y. Han et al., "Suomi NPP CrIS measurements, sensor data record algorithm, calibration and validation activities and record data quality," J. Geophys. Res. 118(22), 12734-12748 (2013).

9. F. Casoli et al., "IASI: summary of a success story and perspective," in 10th IASI Conf. https://iasi.cnes.fr/sites/default/files/drupal/201612/default/bpc_iasi-conference4-0_03_ iasi_story_casoli.pdf (2016).

10. C. Camy-Peyret et al., "Comparison of IASI-A and IASI-B L1C data on the Metop satellites: monitoring of radiometric and spectral performances and possible use for climate studies," in EUMETSAT Meteorol. Satell. Conf. and AMS Satell. Meteorol. Oceanogr. and Climatol. Conf. (2013).

11. M. Bouillon et al., "Ten-year assessment of IASI radiance and temperature," Remote Sens. 12, 2393 (2020).

12. L. Wang and Y. Chen, "Inter-comparing SNPP and NOAA-20 CrIS toward measurement consistency and climate data records," IEEE J. Sel. Top. Appl. Earth Obs. and Remote Sens. 12(7), 2024-2031 (2019).

13. D. Tobin et al., "SNPP CrIS side 2 radiometric calibration and radiometric uncertainty," SNPP CrIS Side2 beta/provisional maturity review (2019)

14. F. Yu et al., "Evaluations of diurnal calibration variation and scan angle emissivity calibration for GOES imager infrared channels," IEEE Trans. Geosci. Remote Sens. 51(1), 671-683 (2013).

15. M. Goldberg et al., "The global space-based inter-calibration system," Bull. Am. Meteorol. Soc. 92, 467-475 (2011). 
16. X. Wu, T. Hewison, and Y. Tahara, "GSICS GEO-LEO inter-calibration: baseline algorithm and early results," Proc. SPIE 7456, 745604 (2009).

17. T. Hewison et al., "GSICS inter-calibration of infrared channels of Geostationary Imagers using Metop/IASI," IEEE Trans. Geosci. Remote Sens. 51(3), 1160-1170 (2013).

18. P. Minnis and M. Khaiyer, "Anisotropy of land surface skin temperature derived from satellite data," J. Appl. Meteorol. 39, 1117-1129 (2000).

19. GOES-R Series Program, "GOES-R Series Mission Requirements Documents (MRD)," US DOC/NOAA/NESDIS and NASA, 2021, https://www.goes-r.gov/syseng/docs/MRD .pdf.

20. Z. Wang et al., "Radiometric quality assessment of GOES-16 ABI L1b images," Proc. SPIE 10764, 107651T (2018).

21. F. Yu, X. Wu, and Z. Wang, "G16 ABI B07 cold scene bias to IASI," in GSICS Annu. Meeting, Frascati (2019).

22. F. Yu et al., "Early radiometric calibration performances of GOES-16 advanced baseline imager," Proc. SPIE 10402, 104020S (2017).

23. F. Yu et al., "Validation of early GOES-16 ABI on-orbit geometrical calibration accuracy using SNO method," Proc. SPIE 10402, 104020 U (2017).

24. A. Okuyama, et al. "Preliminary validation of Himawari-8/AHI navigation and calibration," Proc. SPIE 9607, 96072E (2015).

25. K. Bessho et al., "An introduction to Himawari-8/9 - Japan's new-generation geostationary meteorological satellites," J. Meteorol. Soc. Jpn. 94, 151-183 (2016).

26. T. Tabata et al., "Himawari-8/AHI latest performance of navigation and calibration," Proc. SPIE 9881, 98812J (2016).

27. X. Wu and T. Schmit, "GOES-16 ABI Level1b (L1b) and Cloud and Moisture Imagery (CMI) release full data quality," 2017, https://www.ncdc.noaa.gov/sites/default/files/ attachments/README_ABI-L1b-CMI_Provisional_Maturity.pdf.

28. F. Yu et al., "Validation of GOES-16 ABI infrared spatial response uniformity," Proc. SPIE 10764, 107640F (2018).

29. Z. Wang et al., "The possible discrepancy between the ICT PRT temperatures calculated by CWG and GS," in GOES-R CWG Meeting (2018).

30. X. Wu and F. Yu, "Spectral response function correction I: theory," IEEE Trans. Geosci. Remote Sens. 51(3), 1215-1223 (2013).

31. F. Yu and $\mathrm{X}$. Wu, "Spectral response function correction II: application," IEEE Trans. Geosci. Remote Sens. 5(3), 1200-1214 (2013).

32. J. Taylor et al., "Calibration validation of the GOES-16 Advanced Baseline Imager (ABI) with the high-altitude aircraft based Scanning High-resolution Interferometer Sounder (S-HIS)," in Opt. Sens. and Sens. Congr. (2019).

33. M. Cook et al., "An independent post-launch validation methodology for ABI thermal emissive surface channels using Moored buoys bulk temperature measurements," in Am. Meteorol. Soc., Boston, Michigan (2020).

34. R. X. Johnson and M. Weinreb, "GOES-8 imager midnight effects and slope correction," Proc. SPIE 2812, 596-607 (1996).

35. X. Shao et al., "Characterization and monitoring of GOES-16 ABI stray light and comparison with Himawari-8 AHI and GOES-17 ABI," J. Appl. Remote Sens. 15(1), 017503 (2021).

36. NOAA GOES-R CWG, "STAR GOES Calibration," https://www.star.nesdis.noaa.gov/ GOESCal/ (2021).

37. NOAA GOES-R CWG, "GOES ABI Calibration Events Log," https://www.star.nesdis.noaa .gov/GOESCal/goes_SatelliteAnomalies.php (2021).

Fangfang Yu is the lead of GOES-R ABI cal/val support team at the Cooperative Institute for Satellite Earth System Studies (CISESS), University of Maryland, College Park, Maryland, supporting the operational calibration of NOAA's GOES imaging instruments. She received her BS degree in 1991 and MS degree in 1994 from Peking University, China, and her PhD from the University of Kansas in 2002. She has been supporting and working on the calibration and validation of NOAA's operational optical instruments since 2005. 
Xiangqian Wu coleads the GOES-R Calibration Working Group (CWG) at NOAA in Maryland, USA, specializing in ABI calibration. He has been leading the operational calibration for NOAA's AVHRR on POES since 2002, Imager and Sounder on GOES since 2004, and OMPS on S-NPP between 2010 and 2014. He has been a member of the WMO-sponsored Global Space-based Inter-Calibration System (GSICS) Research Working Group since its inception and served as its first chair.

Hyelim Yoo received her MS/PhD degree in meteorology in atmospheric and oceanic sciences from the University of Maryland, College Park, Maryland, in 2012. Her research interests include remote sensing, model evaluation, and satellite sensor calibration/validation.

Haifeng Qian is a visiting associate research scientist at CISESS/ESSIC, University of Maryland, College Park. He received his PhD in 2008 from the University of Maryland and bachelor's degree in 1999 and his master's degree in 2002 from Nanjing University, China. As a member of NOAA's GOES-R CWG, his main responsibility was to monitor the performance of the GOES-16/17 ABI instruments to support their on-orbit calibration, characterization, and to resolve miscellaneous calibration anomalies.

Xi Shao received his BS degree in space physics from the University of Science and Technology of China in 1996, his $\mathrm{PhD}$ in astronomy in 2001, and his MS degree in electrical engineering with microelectronics major in 2004, both from the University of Maryland, College Park, Maryland. He is currently an associate research scientist at CISESS, Earth System Science Interdisciplinary Center (ESSIC), University of Maryland.

Zhipeng Wang received his BS and MS degrees in optoelectronics from Department of Precision Instrument and Mechanology, Tsinghua University, Beijing, China, in 2000 and 2003, respectively, and his $\mathrm{PhD}$ in optics from the University of Arizona, Tucson in 2008. He is currently a principal research scientist at Science Systems and Applications Inc., Greenbelt, Maryland and a member of NASA/GSFC Independent Calibration Team for CLARREO Pathfinder.

Robbie Iacovazzi is a calibration engineer at NOAA/NESDIS Center for Satellite Applications and Research. For over two decades, he has performed instrument and product integrity cal/val activities for space-based microwave sounding and VNIR imaging radiometers manifested on NOAA operational and NASA research satellites. 